\title{
The Influence of Loading Rate on Direct and Indirect Tensile Strengths: Laboratory and Numerical Methods
}

\author{
Jie Liu $\mathbb{D}^{1,2}$ Gangyuan Jiang, ${ }^{1}$ Taoying Liu, ${ }^{3}$ and Qiao Liang ${ }^{1,2}$ \\ ${ }^{1}$ Department of Building Engineering, Hunan Institute of Engineering, Xiangtan 411104, Hunan, China \\ ${ }^{2}$ Hunan Provincial Key Laboratory of Intelligent Disaster Prevention-Mitigation and Ecological Restoration in Civil Engineering, \\ Hunan Institute of Engineering, Xiangtan 411104, Hunan, China \\ ${ }^{3}$ School of Resources and Safety Engineering, Central South University, Changsha 410083, Hunan, China \\ Correspondence should be addressed to Jie Liu; 517418144@qq.com
}

Received 18 July 2021; Revised 5 October 2021; Accepted 25 October 2021; Published 29 November 2021

Academic Editor: Pengfei Wang

Copyright (C) 2021 Jie Liu et al. This is an open access article distributed under the Creative Commons Attribution License, which permits unrestricted use, distribution, and reproduction in any medium, provided the original work is properly cited.

\begin{abstract}
To investigate different responses of direct and indirect tensile strengths to loading rate, direct and indirect tension tests were performed on sandstone, rust stone, and granite specimens. Typical load curves indicate that a peak tensile stress frequently appears before the second peak stress, used to calculate the tensile strength in indirect tension tests. As expected, increase in the loading rate increases the tensile strength. In addition, the calculated tensile strengths of the indirect tension tests are frequently higher. Interestingly, the increase ratio of the tensile strength with the increase in the loading rate in indirect tension tests is higher. To verify the above results, crack propagation and stress evolution in direct and indirect tension tests were dynamically monitored using PFC 3D. For direct tension tests, specimens fail at the peak tension point, corresponding to the tensile strength. However, for indirect tension tests, minor cracks, composing of continuous microcracks, form before the peak stress and accompany with the decreased slope of the compression curve. At the peak point, tensile stresses significantly concentrate at the crack tips and further cause large-scale crack propagation. In addition, the initiation stress instead of the peak tensile stress is closer to the tensile strength, obtained from the direct tests for the same loading rate.
\end{abstract}

\section{Introduction}

Fractures occur in extensive materials including alloys and rocks $[1,2]$. Tensile fractures form in rocks when tensile stress exceeds the tensile strength. Direct tension (DT) tests and Brazilian tension (BT) tests (indirect tensile tests) are frequently used to measure the tensile strength of rocks [2-4]. In DT tests, rock specimens are commonly cylindrical and dog-bone-shaped. When the tensile stress reaches a critical value, failures frequently occur in the middle part of the specimens [5-8], and the tensile strength can be determined by the following equation :

$$
\sigma_{t}=\frac{P}{A},
$$

where $\sigma_{t}, P$, and $A$ are the tensile strength, the peak tensile force, and the section area of the specimen, respectively.
In BT tests, cylinder specimens are compressed to split the specimens (Figure 1(a)). The following equation depicts the tensile strength [9].

$$
\sigma_{t}=\frac{2 P}{\pi D t},
$$

where $\sigma_{t}, P, D$, and $t$ are the tensile strength, the compression force at failure, and the diameter and thickness of the specimen, respectively.

However, tension cracks may initiate beneath the contact parts between the loading plate and rock specimen instead of the center of the specimen $[10,11]$. To avoid this phenomenon, curved and flattened loading patterns have been proposed [12-16]. For the curved loading tests, suggested by ISRM, the radius of the jaw is 1.5 times the specimen radius $[17,18]$ to ensure the accuracy of the tests (Figure 1(b)). For the flattened 


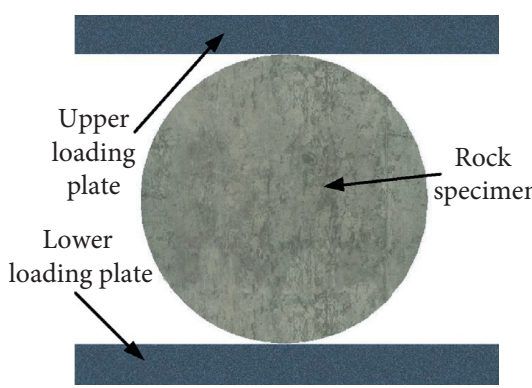

(a)

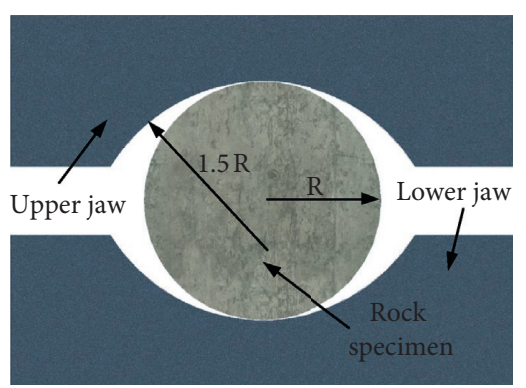

(b)

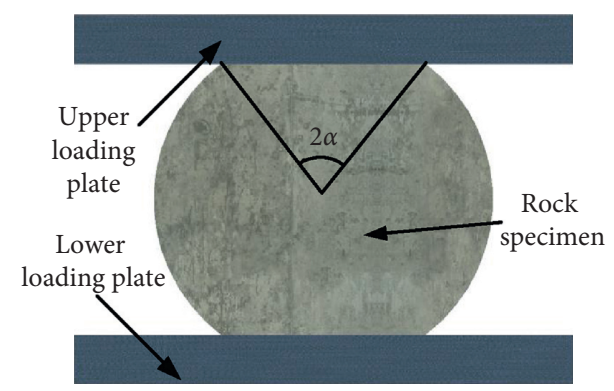

(c)

Figure 1: Typical Brazilian tests: (a) flat loading, (b) curved loading, and (c) Flattened loading.

Brazilian tension (FBT) tests (Figure $1(\mathrm{c})$ ), the tensile strength is given as $[19,20]$

$$
\sigma_{t}=\frac{2 P\left(2 \cos ^{3} \alpha+\cos \alpha+\sin \alpha / \alpha\right)^{2} \alpha}{8 \pi D t \sin \alpha(\cos \alpha+\sin \alpha / \alpha)},
$$

where $\sigma_{t}, P, \alpha, D$, and $t$ are the tensile strength, the compression force at failure, the loading angle, and the diameter and thickness of the specimen, respectively.

Some difficulties exist in the specimen preparation and the loading processes of the DT tests [19]. Thus, the more convenient $\mathrm{BT}$ and $\mathrm{FBT}$ tests are more common. However, the calculated tensile strengths of BT and FBT tests may vary from those of the DT tests $[4,17]$. This variation may result from the adoption of the compression force at failure in equations (2) and (3). Frequently, the compression force at failure is the peak compression force in the BT and FBT tests $[20,21]$. However, the compression force at crack initiation, based on the theoretical analysis (equations (2) and (3)), may vary from the peak compression force because minor crack propagation may occur and hardly causes obvious force drops $[8,21-23]$. The laboratory tests by Patel and Wang have verified that minor cracks may form before the peak compression force $[8,23]$. However, the underlying mechanism for this phenomenon remains unclear because of the limitation on laboratory equipment [22]. In addition, loading rate is a critical factor, affecting the rock strength $[24,25]$. The DT tests by Cen and $\mathrm{Li}$ indicated that tensile strength positively relates to the strain rate $[4,5]$. The Brazilian tests by Xiong, $\mathrm{Wu}$, and Wang obtained similar conclusions on BT strength and loading rate $[22,24,25]$. The fracture mechanisms for direct tension (DT) and indirect tension (BT and FBT) tests might be different. However, the mechanical responses of these methods to the loading rate lack sufficient investigations.

Thus, the present study first performed DT, BT, and FBT tests on sandstone, rust stone, and granite specimens for various loading rates. Then, because of the advantages of numerical methods in crack development [26-29], Particle Flow Code (PFC 3D) was applied to verify the laboratory results and to investigate the underlying mechanism.

\section{Laboratory Tests and Results}

2.1. Laboratory Specifications. Using the WDW-100 testing machine with a wide loading rate range $(0.01-100 \mathrm{~mm} / \mathrm{min})$, DT, BT, and FBT tests were performed on sandstone, rust stone, and granite specimens (Figure 2). The uniaxial compression strengths of these specimens were $64.8 \mathrm{MPa}$, 94.2 $\mathrm{MPa}$, and $150.8 \mathrm{MPa}$, respectively. The corresponding elastic moduli were $21.2 \mathrm{GPa}, 28.8 \mathrm{GPa}$, and $42.7 \mathrm{GPa}$, respectively. To investigate the influence of the loading rate on the tensile strength, the displacement-controlled loading rates (constant) were $0.01,0.05,0.1,1$, and $10 \mathrm{~mm} / \mathrm{min}$, respectively. When the postpeak loads were less than $70 \%$ of the peak loads, the tests ceased. For the direct tension tests, the specimens were dog-bone-shaped (Figure 2(a)) to ensure tension fractures occur near the middle part of the specimens. These specimens were fixed in two steel holders, connecting to the tension rods with ball joints. In the loading process, the steel holders were compressed by two clamps to ensure sufficient contact between the rock specimens and the holders. For the BT tests using an arch jaw (Figure 2(b)), the radius of the arch jaw was 1.5 times the radius of the specimens with a radius and a thickness of $25 \mathrm{~mm}$ [17]. The loading angles of the FBT specimens with a thickness of $25 \mathrm{~mm}$ were $5^{\circ}, 10^{\circ}$, and $15^{\circ}$, respectively (Figure $2(\mathrm{c})$ ). Figures 2(a)-2(c) show the dimensions of the specimens. In total, 15 direct tension tests, 15 BT tests, and 45 FBT tests were performed.

\subsection{Laboratory Test Results}

2.2.1. Tensile Failure. Figure 3 shows the typical DT failures for various loading rates. The uneven fracture surfaces, locating near the middle part of the specimens, indicate that tension fractures occur. For the typical rock fractures in the $\mathrm{BT}$ and FBT tests, the curved red dash lines, representing the trajectories of the fractures, show that tension fractures occur after compression (Figure 4). Similar phenomena occurred in the other direct and indirect tension tests (the figures are not shown).

2.2.2. Tensile Strengths. According to equations (1)-(3), Figure 5 depicts the measured tensile stresses for the rust stone specimens at a loading rate of $0.05 \mathrm{~mm} / \mathrm{min}$. For the 


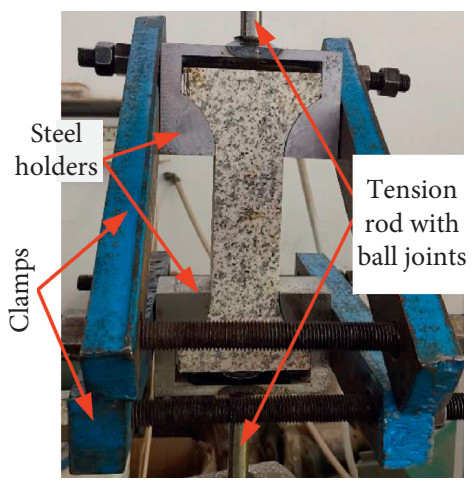

(a)

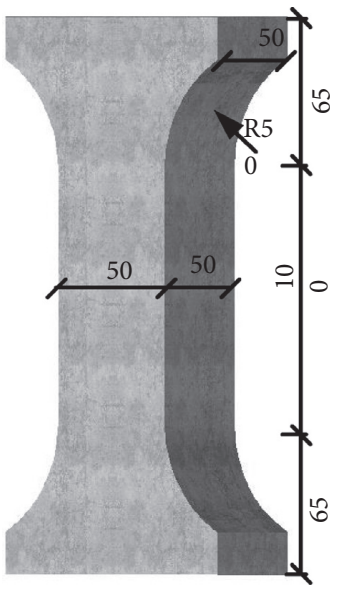

(d)

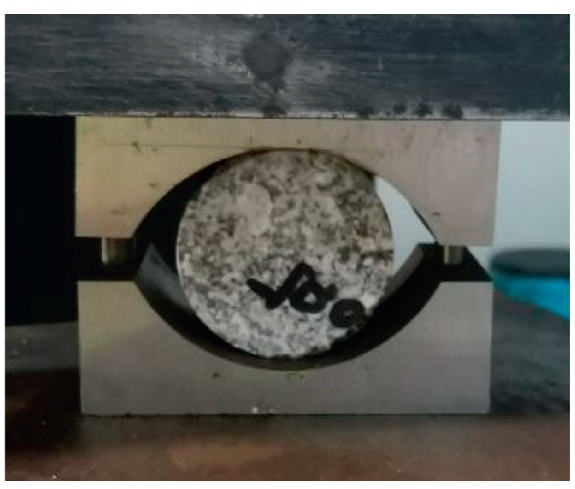

(b)

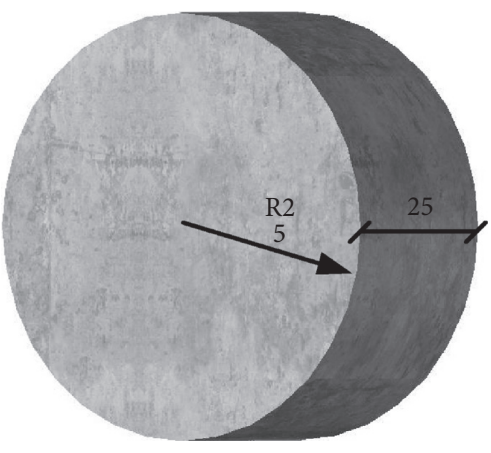

(e)

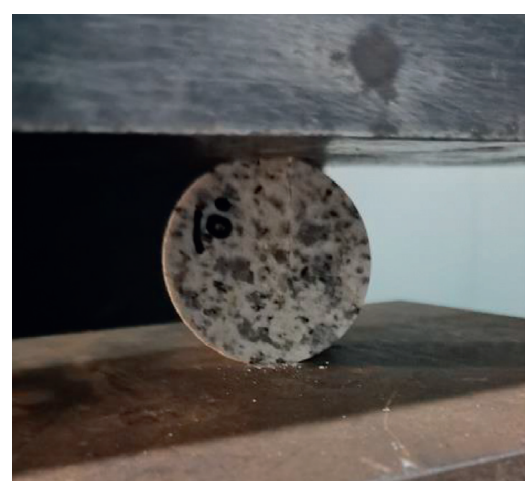

(c)

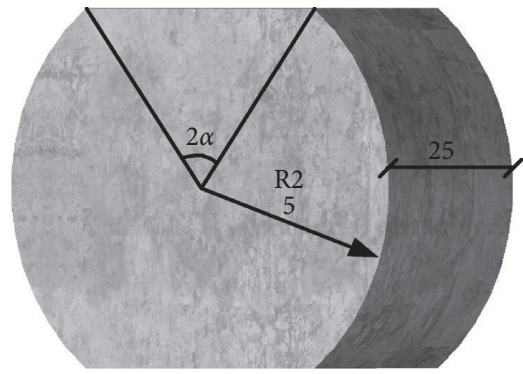

Unit: $\mathrm{mm}$

Figure 2: Laboratory tests: $(\mathrm{a}-\mathrm{c}) \mathrm{DT}, \mathrm{BT}$, and FBT tests; $(\mathrm{d}-\mathrm{f})$ corresponding specimens' geometries.

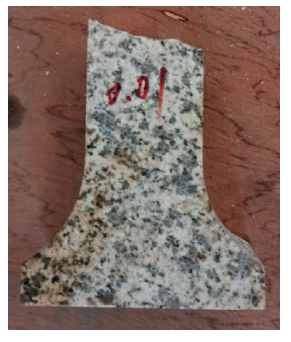

(a)

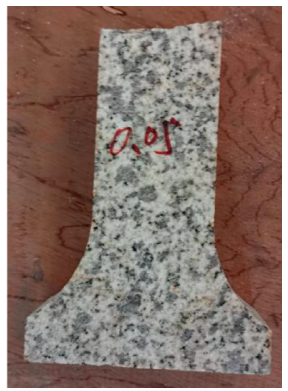

(b)

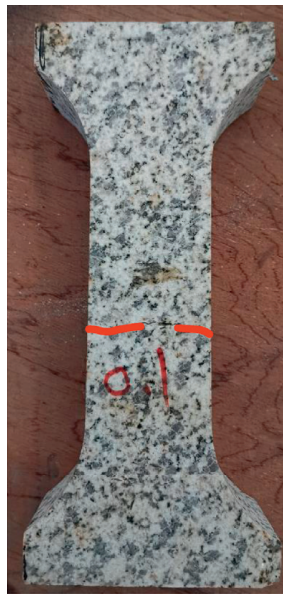

(c)

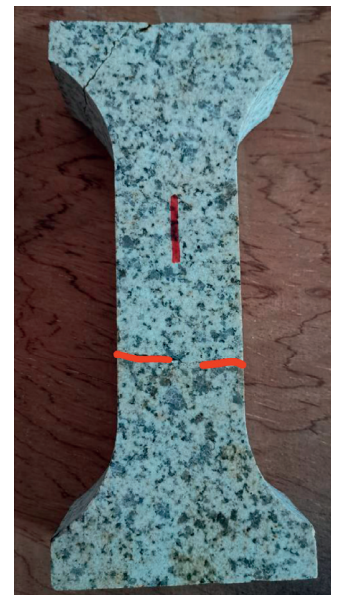

(d)

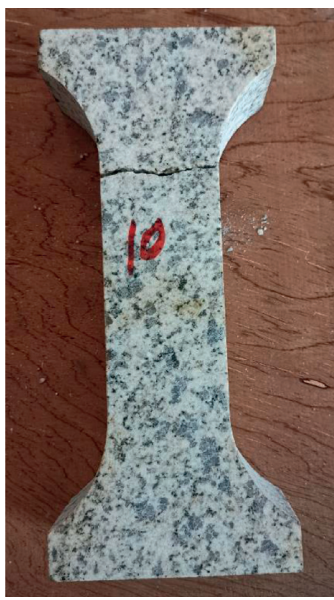

(e)

Figure 3: Typical failures after DT tests: (a-e) rock failures for the loading rates of $0.01,0.05,0.1,1$, and $10 \mathrm{~mm} / \mathrm{min}$, respectively, for the rust stones. 


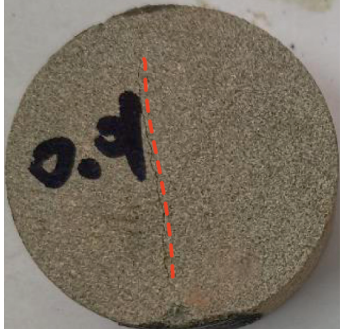

(a)

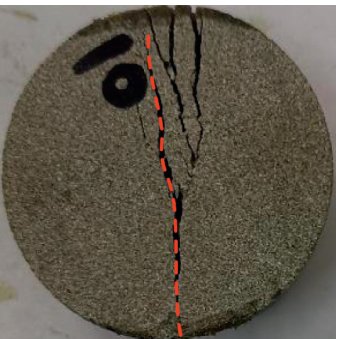

(e)

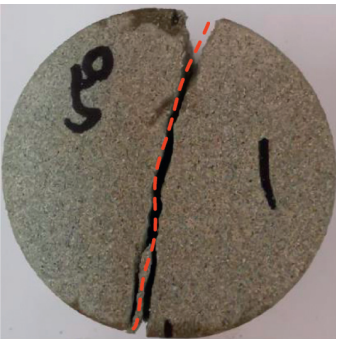

(i)

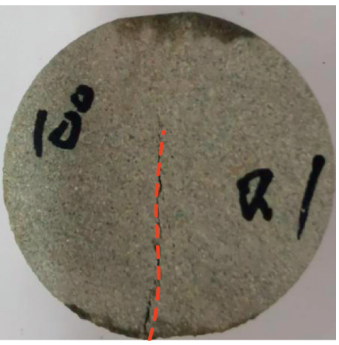

(m)

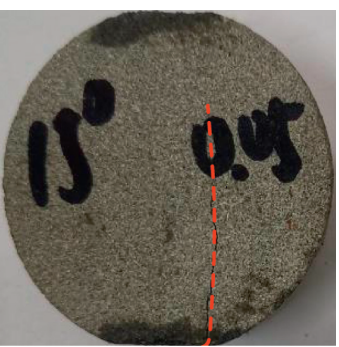

(q)

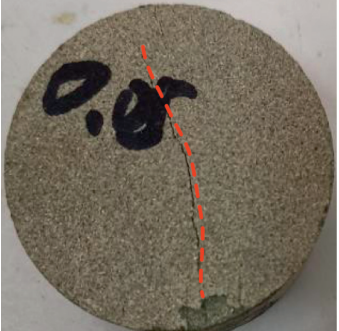

(b)

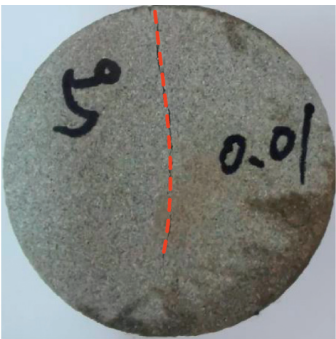

(f)

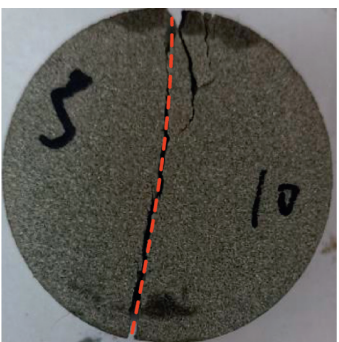

(j)

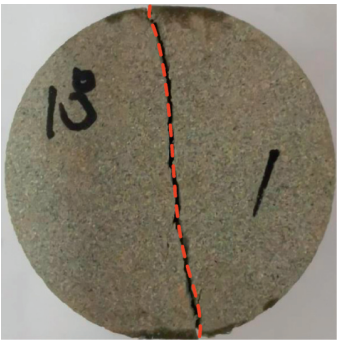

(n)

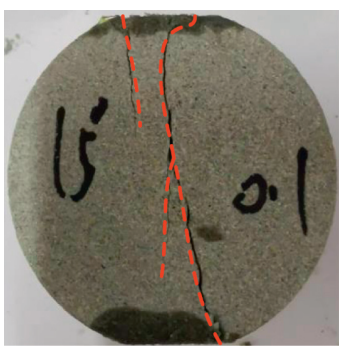

(r)

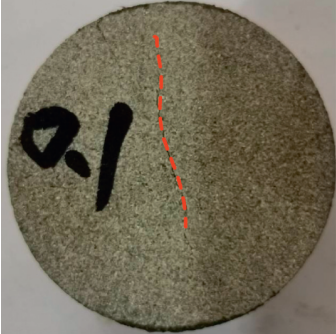

(c)

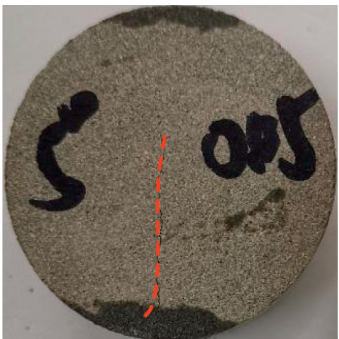

(g)

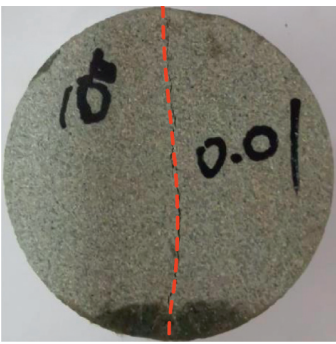

(k)

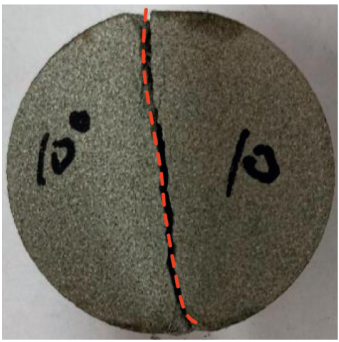

(o)

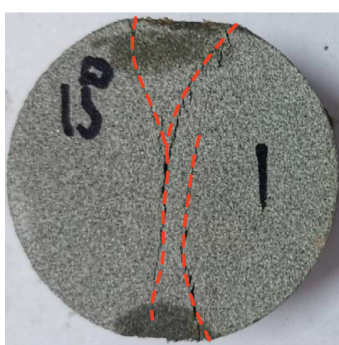

(s)

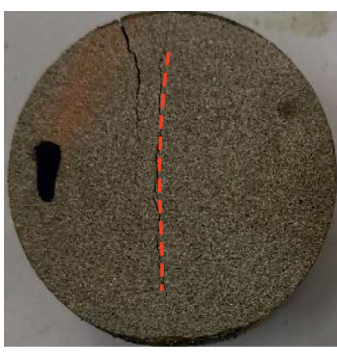

(d)

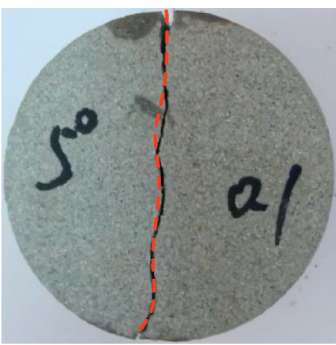

(h)

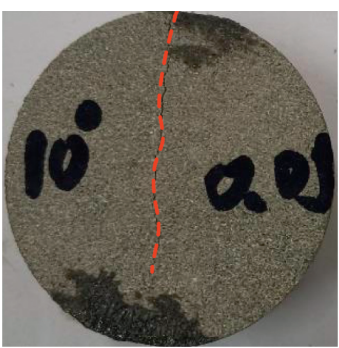

(1)

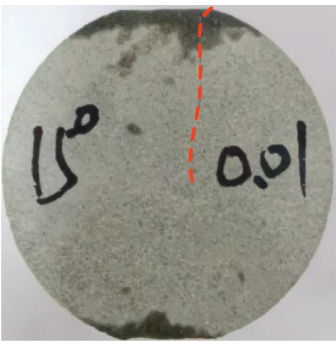

(p)

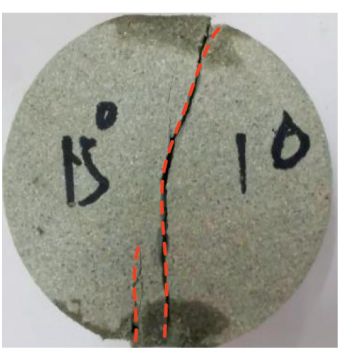

(t)

FIgURE 4: Typical failures after indirect tests: (a-e) rock failures at the loading rates of $0.01,0.05,0.1,1$, and $10 \mathrm{~mm} / \mathrm{min}$, respectively, for the BT tests; $(\mathrm{f}-\mathrm{j}),(\mathrm{k}-\mathrm{o})$, and $(\mathrm{p}-\mathrm{t}) \mathrm{FBT}$ tests with the loading angles of $5^{\circ}, 10^{\circ}$, and $15^{\circ}$, respectively. 


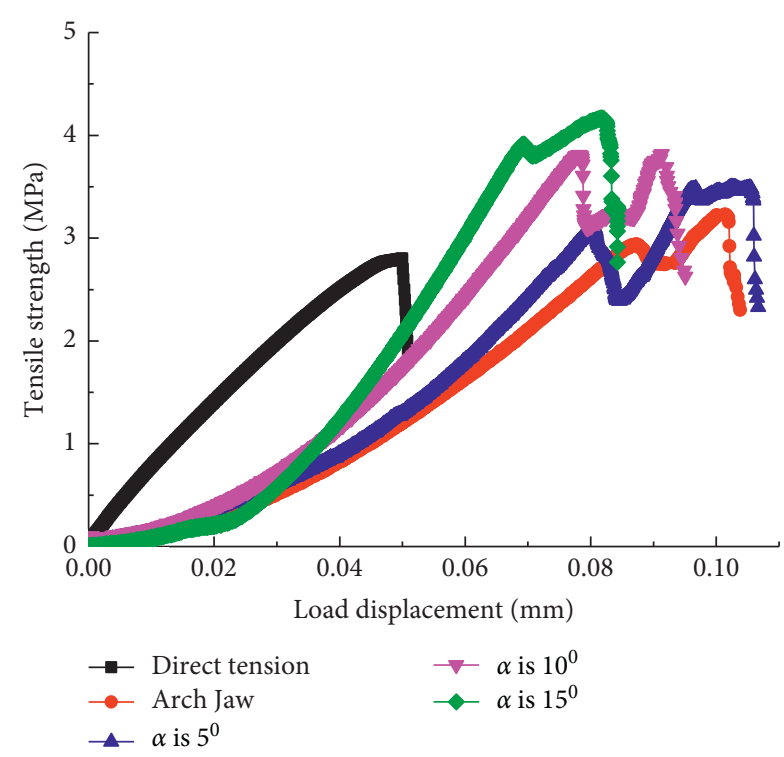

Figure 5: Typical loading curves for the loading rate of $0.05 \mathrm{~mm} /$ $\min$.

direct tension test, first, the tensile stress approximately linearly increases with the increase in the axial displacement. When the axial displacement reaches about $0.05 \mathrm{~mm}$, the peak tensile stress with a value of $2.8 \mathrm{MPa}$ is reached. For the BT and FBT tests, it is interesting to find that the measured tensile stresses first slowly increase with the increase in the loading displacement. Then, the increase rates of the tensile stresses elevate. With the further increase in the load displacement, the first peaks in the stress curves form. After these peaks, the tensile stresses dramatically drop and then sharply increase. Subsequently, the second peaks in the stress curves appear and are followed by sharp decreases to $70 \%$ of the second peaks in the stress curves. Previous studies indicated that the fluctuations of load curves may relate to crack propagation [23, 28]. Thus, fractures may occur before the second peaks in the stress curves.

Figure 6 shows the fitted DT, BT, and FBT tensile strengths, using the second peaks. Clearly, the direct tensile strengths are lower than the indirect tensile strengths. The calculated tensile strengths for the BT and FBT- 5 specimens, where 5 indicates the loading angle of $5^{\circ}$, are close. In addition, the calculated tensile strengths positively relate to the loading angle for the FBT tests. To further analyze the deviations of the $\mathrm{BT}$ and $\mathrm{FBT}$ tensile strengths from the DT strengths, Figure 7 shows the deviation ratios for various loading rates according to

$$
R_{\text {devi }}=\frac{\sigma_{\text {ind }}-\sigma_{\text {dir }}}{\sigma_{\text {dir }}},
$$

where Rdevi, $\sigma$ ind, and $\sigma$ dir are the deviation ratio from the DT strength, the indirect tensile strength, and the direct tensile strength, respectively.

Figure 7 clearly shows that the deviation ratios positively relate to the loading angle for the FBT tests. The deviation ratios of the $\mathrm{BT}$ are close to those of the FBT- 5 tests.
To analyze the effect of loading rate on the tensile strength, the increase ratios were obtained (Figure 8) using the following equation :

$$
R_{\text {in }}=\frac{\sigma_{t i}-\sigma_{t 0.01}}{\sigma_{t 0.01}},
$$

where $R_{\mathrm{in}}, \sigma_{\mathrm{ti}}$, and $\sigma_{t 0.01}$ are the increase ratio, the tensile strength for various loading rates, and the tensile strength when the loading rate is $0.01 \mathrm{~mm} / \mathrm{min}$, respectively.

Interestingly, the increase ratios for the DT, BT, and FBT tests are different. Especially, for the FBT tests, the increase ratio positively relates to the loading angle.

The above results show that the BT and FBT tests frequently yield higher tensile strengths. Especially for the FBT tests, the tensile strength positively relates to the loading angle. In addition, increase in the loading rate promotes the tensile strength. Interestingly, the increase rates for the BT and FBT tests are higher than those for the DT tests. The fluctuations of the loading curve before the second peaks may be responsible for the differences between the direct and indirect tensile strengths. However, the underlying mechanism remains unclear. In addition, some challenges exist in observing the crack initiation and propagation, using the presently available apparatus [22]. Thus, in the following sections, PFC 3D was applied to dynamically study the fracture processes and the stress evolution in different tension tests.

\section{Numerical Simulations and Results}

3.1. Numerical Preparation. The flat-joint model can properly simulate the fracture process of rock and rock-like materials $[30,31]$. In the flat-joint model, tension bond breakages occur when the normal stress between particles exceeds the tensile strength. The shear strength first obeys the Coulomb criterion when the shear stress is relatively low. Then, shear breakages generate when the shear stress exceeds a critical value. More importantly, the residual shear stress remains because of the friction between the particles [30,31]. In the present study, the DT, BT, and FBT tests on sandstone specimens were simulated (Figure 9) using the flat-joint model. Calibration is essential before simulation tests. Thus, the frequently used "trial and error" method was adopted [32]. First, the elastic modulus of the specimen was calibrated by adjusting the elastic modulus of the particle and the contact. Then, the normal and shear contact strengths were adjusted to calibrate the uniaxial compressive strength. Table 1 lists the micro and macro mechanical properties of the rock specimens. Clearly, the numerical results agree well with the laboratory test results. The computing ability in the laboratory is limited, and thus, the middle tension part of the DT sample $(100 \mathrm{~mm} \times 50 \mathrm{~mm} \times 50 \mathrm{~mm})$ was simulated (Figure 9(a)). The real loading rate of the physical test is different from the particle loading rate in PFC 3D [31, 33]. In the DT tests, the bottom particles were fixed, and the upper (green) particles were displacement-controlled at the constant rates of $0.0006,0.003,0.006,0.06$, and $0.6 \mathrm{~mm} / \mathrm{s}$ to simulate various loading rates. According to the sample geometries in the indirect tests, the BT and FBT models were 


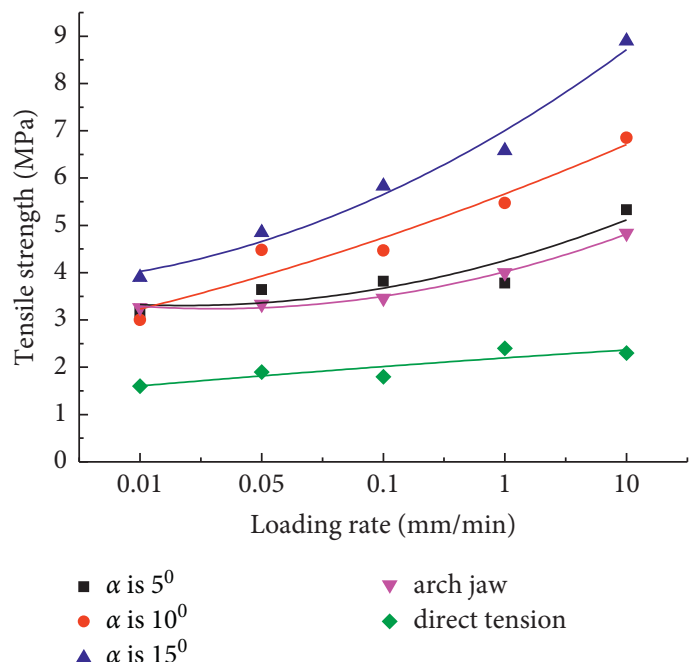

(a)

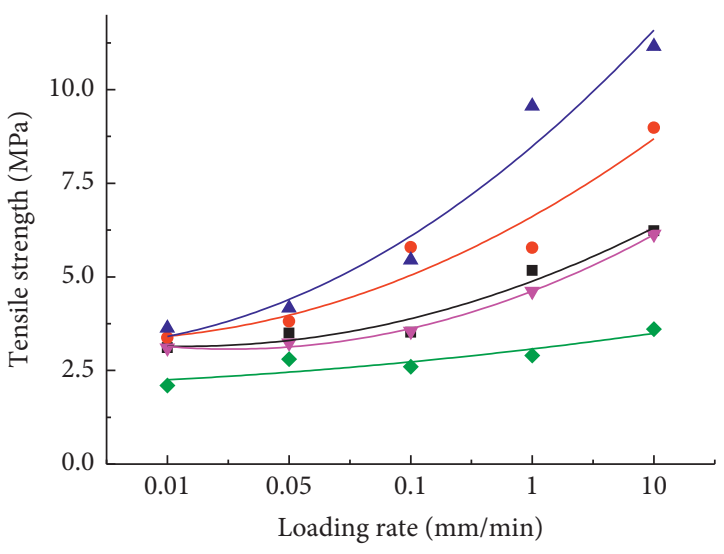

- $\alpha$ is $5^{0}$

- $\alpha$ is $10^{0}$

- $\alpha$ is $15^{0}$

- direct tension

(b)

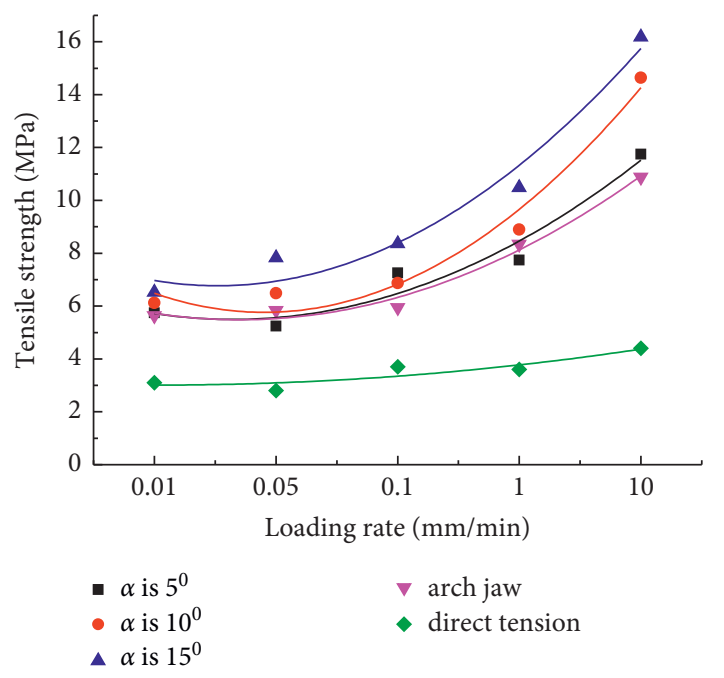

(c)

FIgURE 6: Tensile strengths: (a-c) measured tensile strengths for the sandstone, rust stone, and granite specimens, respectively.

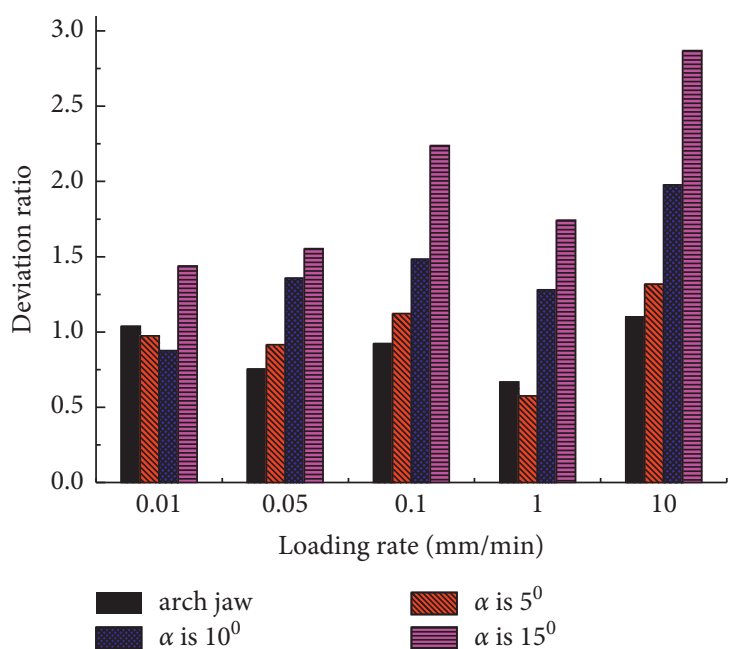

(a)

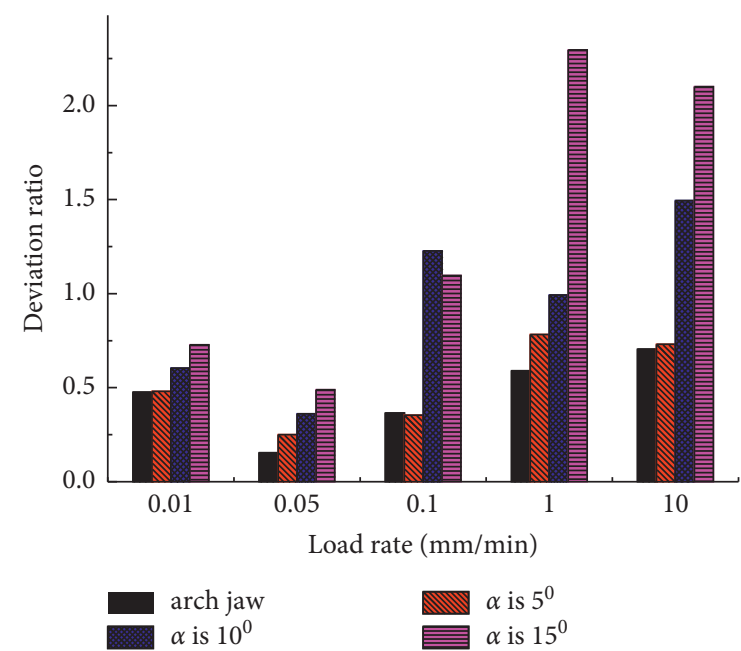

(b)

Figure 7: Continued. 


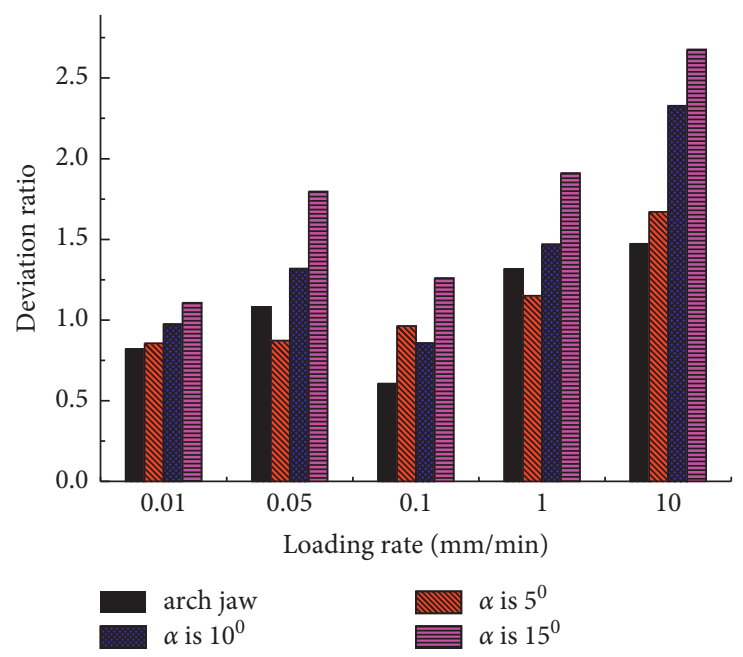

(c)

FIGURE 7: Deviation ratios for the increasing loading rates: $(\mathrm{a}-\mathrm{c})$ deviation ratios for the sandstone, rust stone, and granite stone specimens, respectively.
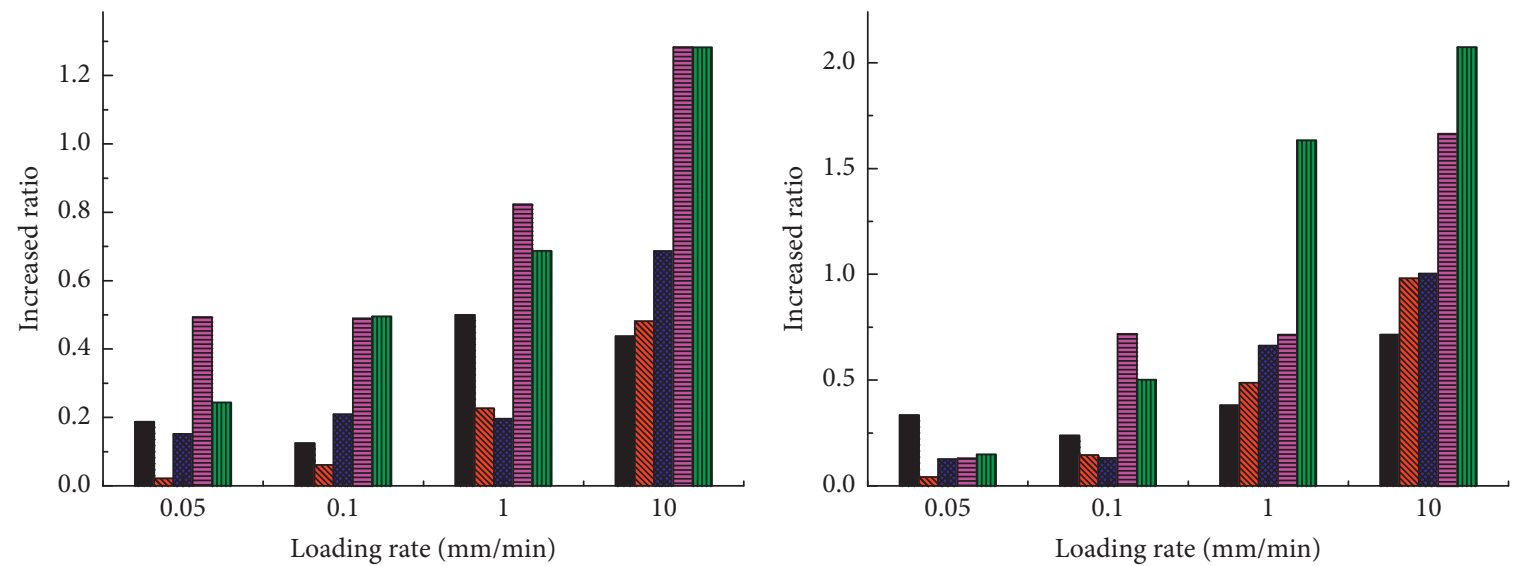

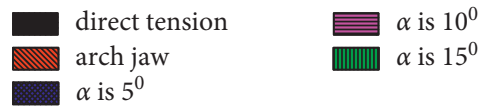

(a)

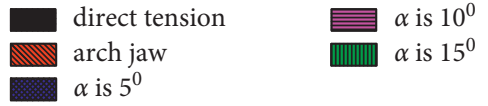

(b)

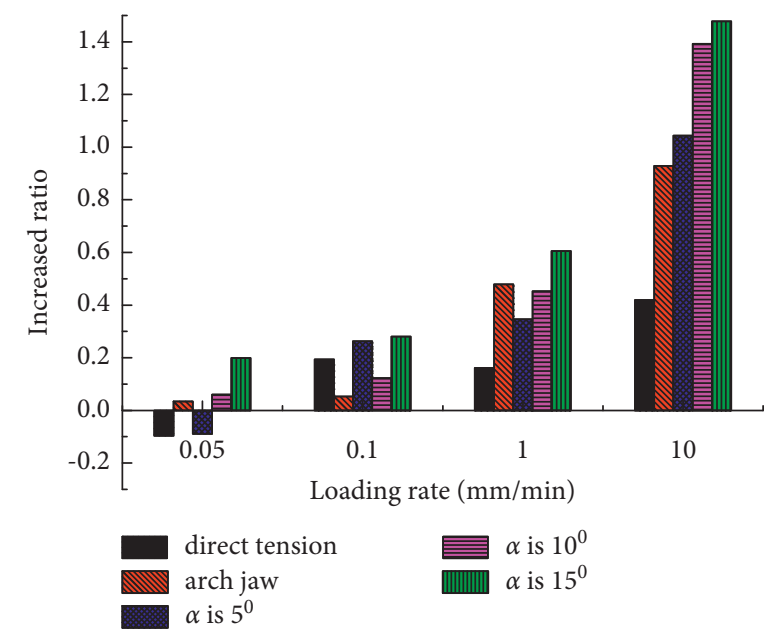

(c)

FIGURE 8: Increase ratios for the increasing loading rates: $(\mathrm{a}-\mathrm{c})$ increase ratios for the sandstone, rust stone, and granite stone specimens, respectively. 


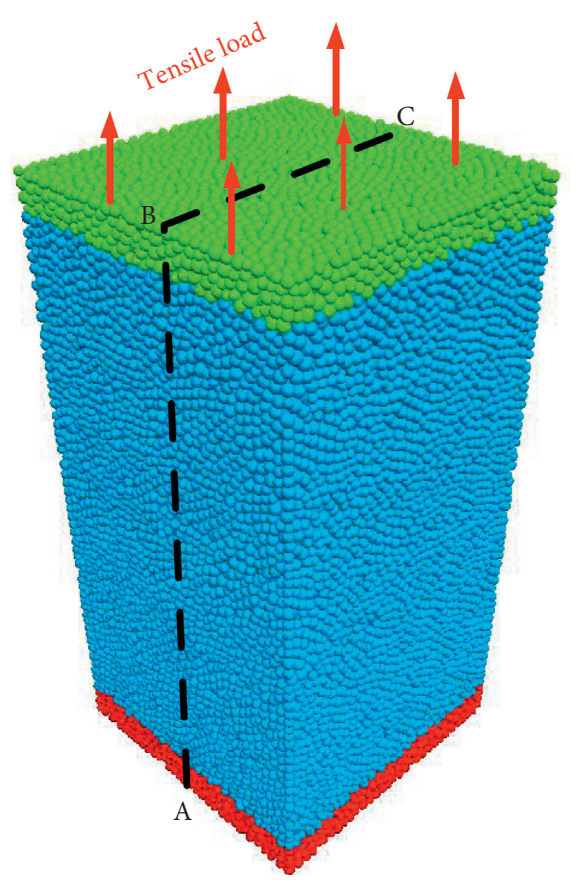

(a)

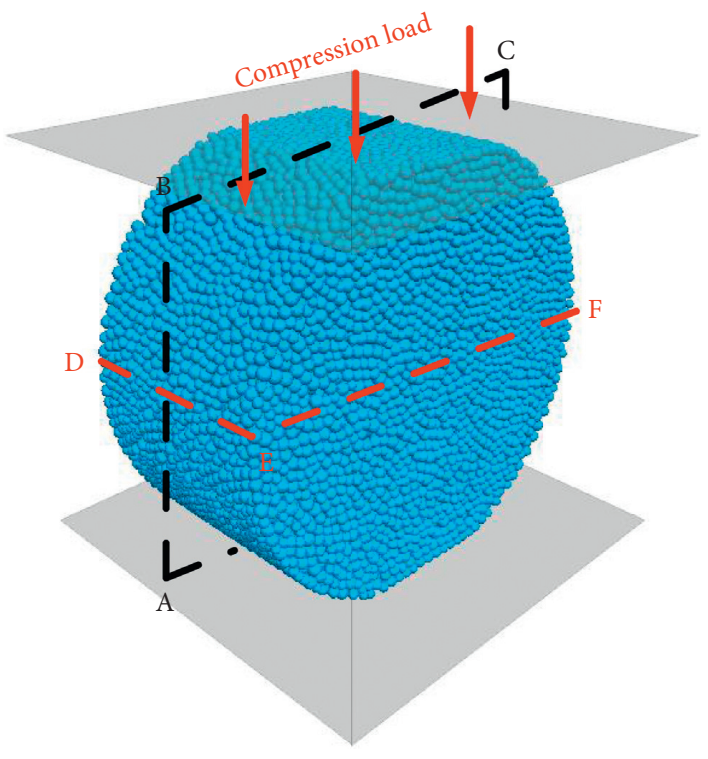

(c)

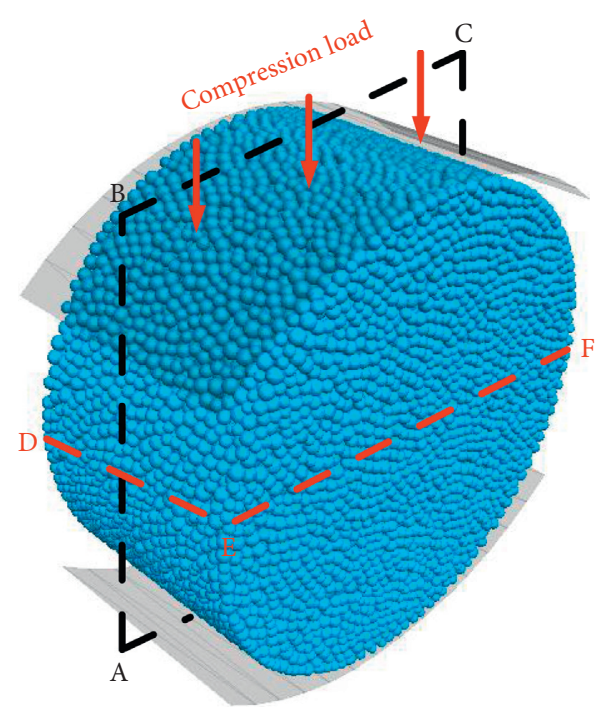

(b)

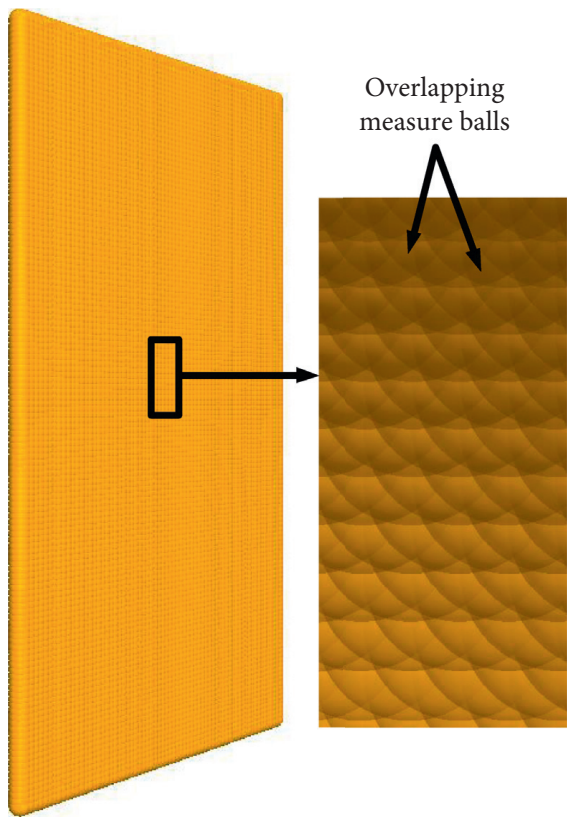

(d)

FIGURE 9: Numerical simulations: (a-c) DT, BT, and FBT models, respectively; (d) stress monitor plane, composing of measure balls.

established (Figures 9(b) and 9(c)). In the compression process, the upper wall was displacement-controlled with the same constant rates listed above. In addition, in the loading process, stress monitor planes (Figure 9(d)), consisting of many overlapping measure balls with a radius of $0.75 \mathrm{~mm}$, were installed. The measure balls can record the tension and shear stresses within the sphere $[22,28,30]$. Thus, by exporting the recorded stresses, stress contours can be drawn. For the DT test, the monitor plane was installed on the ABC plane as shown in Figure 9(a). Two monitor planes ( $\mathrm{ABC}$ and $\mathrm{EDF}$ ) were installed for the $\mathrm{BT}$ and FBT tests
(Figures 9(b) and 9(c)). Moreover, numerical tests were saved for specific steps. After the entire calculation, the final pattern of the main crack, resulting in the failure of the specimen, was determined. Then, by sequential comparisons between two adjacent crack patterns, the initiation point of the main crack can be determined.

3.2. Numerical Results. Figure 10(a) shows the calculated tensile strengths, using the peak forces (equations (1)-(3)). The BT and FBT tests yield higher tensile strengths. In 
TABLE 1: Micro and macro mechanical parameters of sandstone specimens.

\begin{tabular}{lcc}
\hline Microparameters & Value & Macro parameters \\
\hline Particle radius range $(\mathrm{mm})$ & $0.45-0.75$ & Value \\
Particle contact modulus $(\mathrm{GPa})$ & 21 & Uniaxial compression strength $(\mathrm{MPa})$ \\
Particle normal/shear stiffness $(\mathrm{GPa})$ & 21 & \\
Friction coefficient & 0.25 & Young's modulus $(\mathrm{GPa})$ \\
Normal strength of the flat-joint contact $(\mathrm{MPa})$ & 2.5 & \\
Shear strength of the flat-joint contact $(\mathrm{MPa})$ & 28 & 19.8 \\
\hline
\end{tabular}

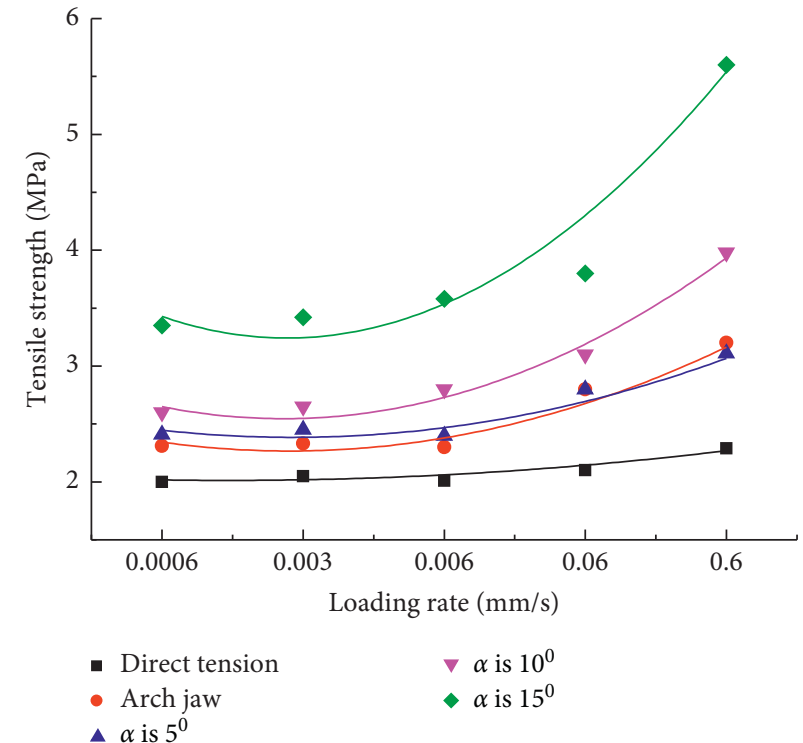

(a)

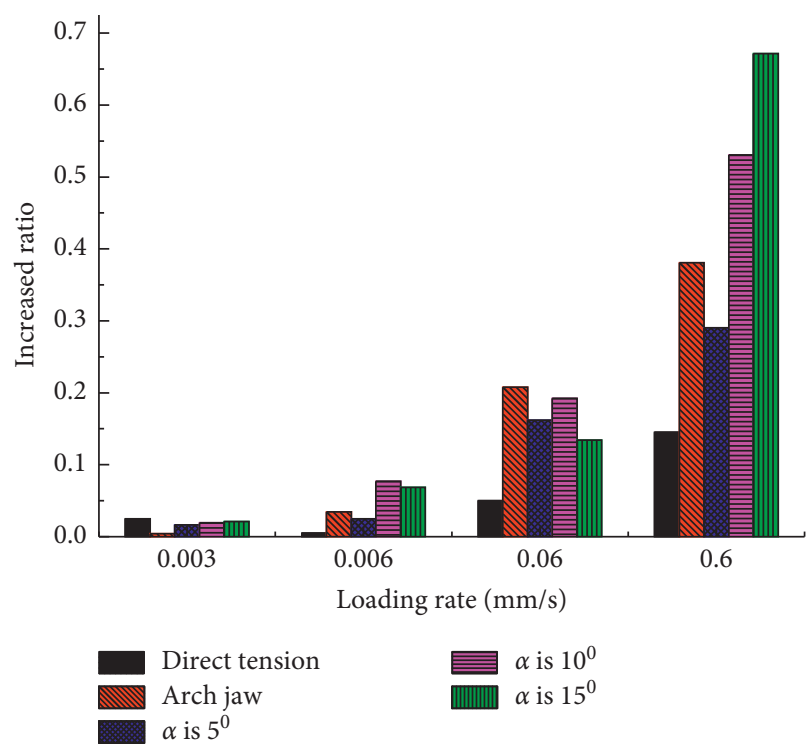

(b)

Figure 10: Numerical results: (a) calculated tensile strength using equations (1)-(3); (b) increase ratio using equation (5).

addition, the increase in the loading angle in the FBT tests promotes the tensile strength. Moreover, compared to the calculated tensile strength with the loading rate of $0.0006 \mathrm{~mm} / \mathrm{s}$, Figure 10 (b) also indicates that the increase ratios for the DT, BT, and FBT tests are different. The FBT tests with relatively larger loading angles are more sensitive to the increase in the loading rate. The above numerical results agree well with the laboratory ones (Figures 6-8). However, the underlying mechanism remains unclear. To further verify the above results, an effort is made to analyze the dynamic crack developments and the corresponding stress evolutions in the DT, BT, and FBT tests.

Figure 11 shows the typical fracture pattern, the calculated tensile stress curve using equation (1), and the tensile crack development in the DT test with a loading rate of $0.06 \mathrm{~mm} / \mathrm{s}$. Clearly, a fracture plane (main crack), penetrating the entire specimen, forms in the middle part of the specimen. Similar cracks, locating near the middle of the specimen, were also observed in laboratory tests (Figure 3). Besides, a secondary crack, partially penetrating the specimen, generates at the upper part. In addition, many minor cracks dispersedly distribute on the surface of the specimen. The tensile stress curve indicates that the tensile stress linearly increases with the increase in the axial displacement. When the displacement increases to about $0.064 \mathrm{~mm}$, a peak

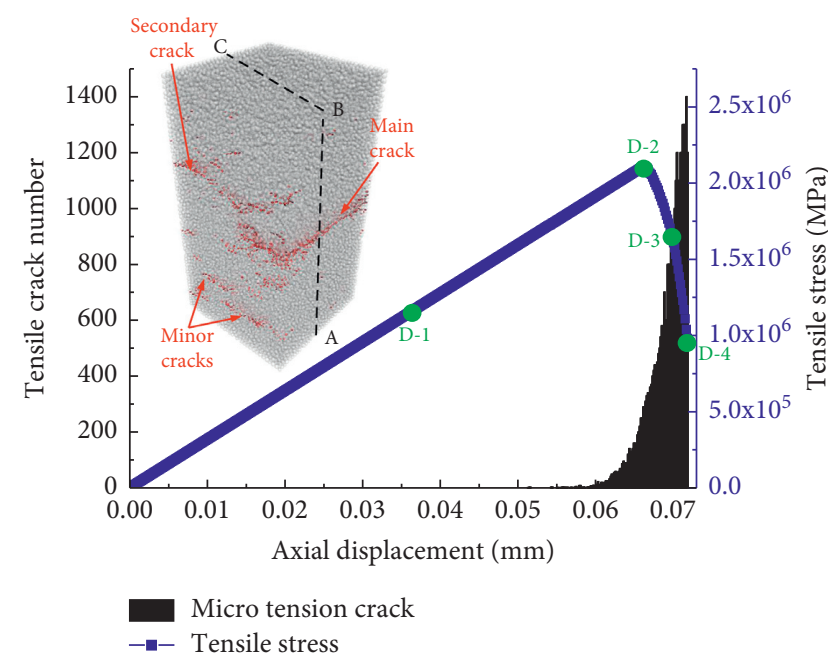

FIgUre 11: The failure pattern, the tensile stress, and the crack development in the DT tests.

stress, equal to about $2.1 \mathrm{MPa}$, occurs. The recorded tensile crack numbers (every $0.0001 \mathrm{~mm}$ in the axial displacement) indicate that microtension cracks sharply accumulate at the peak point. This abrupt microcrack accumulation may result from the crack development. 


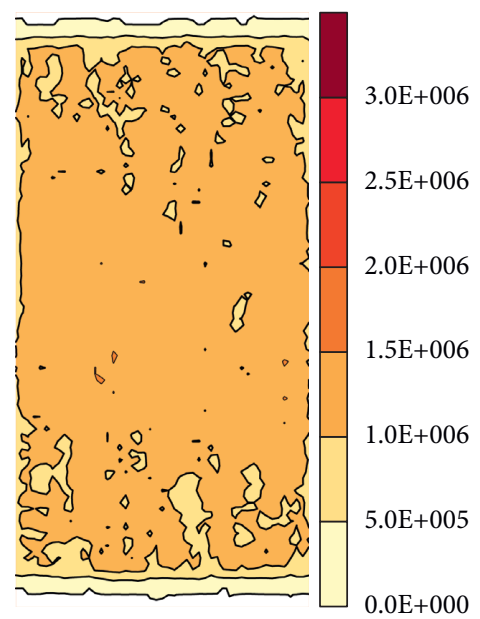

(a)

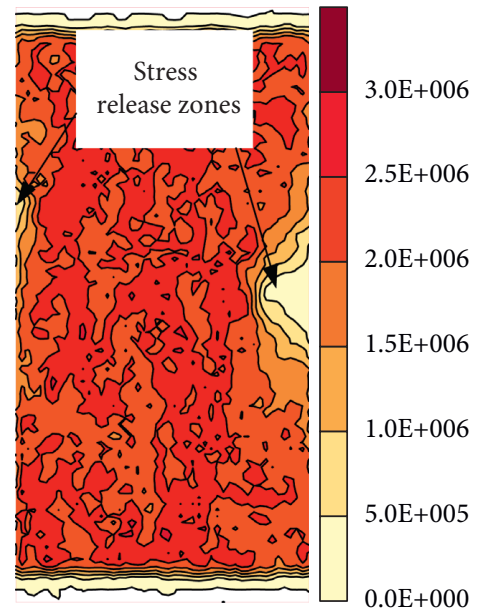

(e)

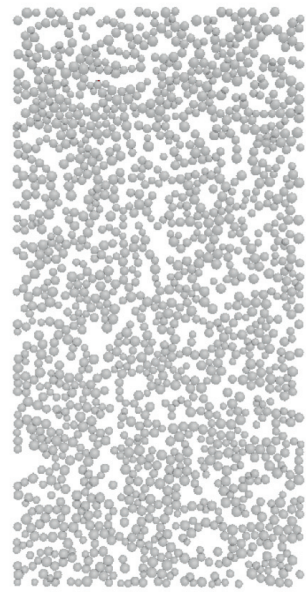

(b)

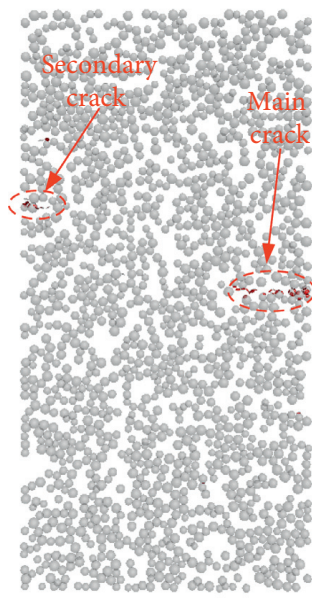

(f)

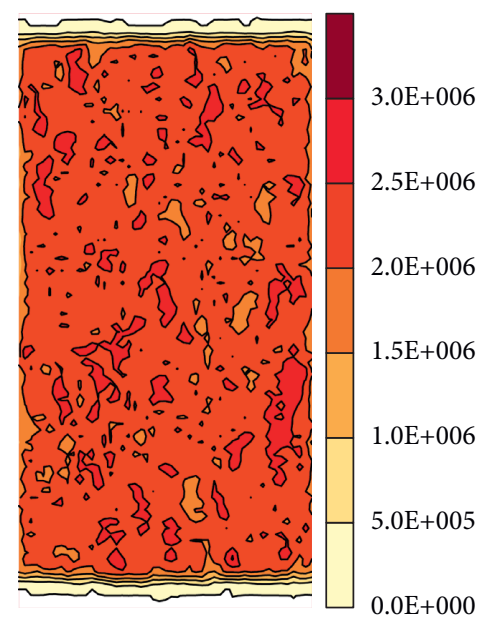

(c)

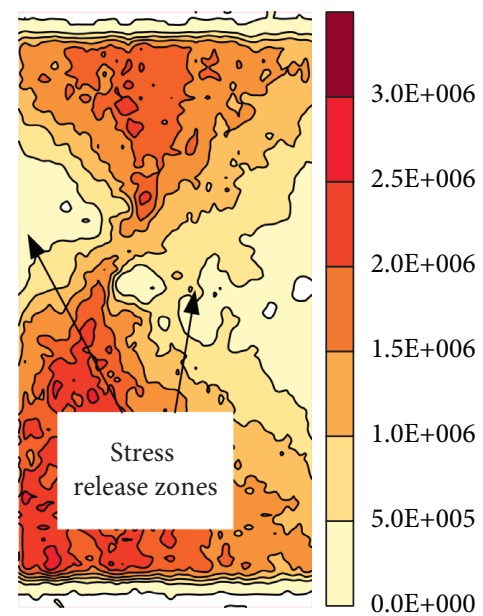

(g)

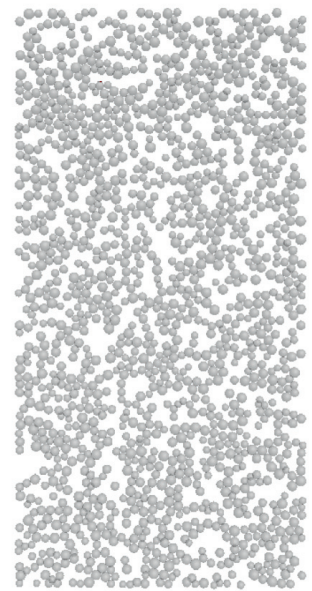

(d)

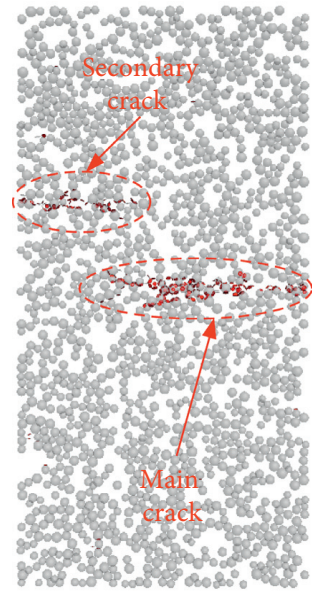

(h)

FIgURE 12: Tensile stresses and crack developments at points (a)-(h).

To verify the above inference, four monitor points D-1 D-4 were installed on the stress curve (Figure 11) to dynamically analyze the fracture and the tensile stress evolution at the stress monitor plane ( $\mathrm{ABC}$ plane). At the monitor point $\mathrm{D}-1$, Figure 12(a) shows that the tensile stress, ranging from 1.0 to $1.5 \mathrm{MPa}$, is approximately uniform on the ABC plane. Minor cracks are absent (Figure 12(b)). At the peak point $\mathrm{D}-2$, the approximately uniform tensile stress with an average value of $2.1 \mathrm{MPa}$ is observed on the $\mathrm{ABC}$ plane (Figure 12(c)). Similarly, microcracks are absent on this plane (Figure 12(d)). The dispersedly distributed cracks may be responsible for the accumulated microcracks (Figure 11) ahead of the peak point. At the point D-3, two stress release zones form (Figure 12(e)). Simultaneously, two cracks (the main and secondary cracks) on the plane form (Figure 12(f)). Clearly, these cracks overlap with the stress release zones. With further increase in the axial displacement, the stress release zones and the cracks increase (Figures $12(\mathrm{~g})$ and $12(\mathrm{~h})$ ). Thus, the above inference is properly verified. It can be concluded that the tensile stress approximately linearly increases with the increase in the axial displacement. When the stress reaches to a critical value (peak strength), cracks initiate and continuously propagate with a further increase in the axial displacement. After the peak strength, cracks significantly propagate and cause the stress to release on the crack propagation path.

For the BT tests, similar to the laboratory failure patterns in Figure 4, Figure 13(a) shows that a crack forms in the middle part of the specimen. The calculated tensile stress using equation (2) first increases with the increase in the compression displacement. When the compression displacement reaches $0.0675 \mathrm{~mm}$, the peak tensile stress occurs. After the peak point, microcracks significantly accumulate. This increase may result from large-scale crack propagation. Interestingly, before the peak point, a microcrack accumulation in a relatively smaller scale occurs when the axial displacement is about $0.06 \mathrm{~mm}$. This minor crack accumulation accompanies with the decreased slope of the calculated tensile stress instead of the fluctuation of the tensile stress. In addition, shear microcracks generate after the peak.

These different phenomena from the DT tests may result from the different crack development and stress conditions. Thus, four monitor points (J-1 J-4) were installed on the 


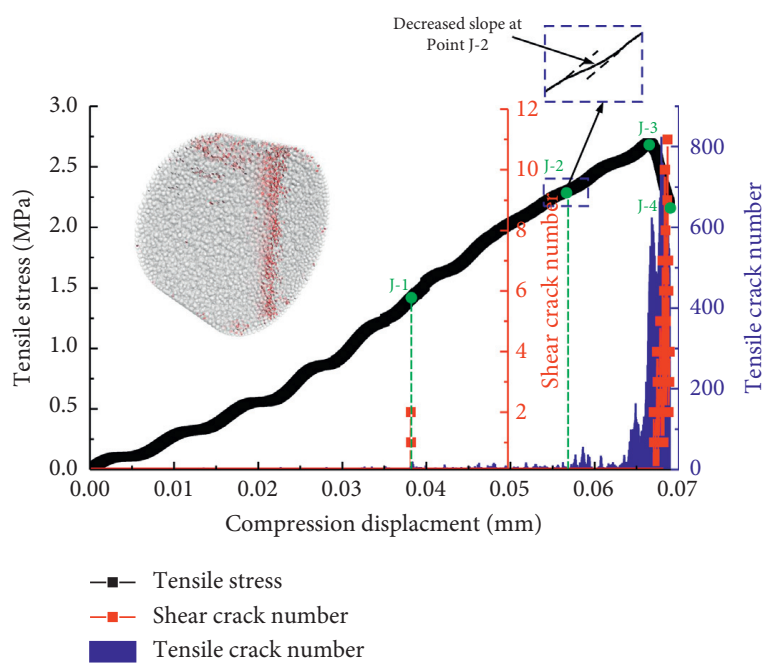

(a)

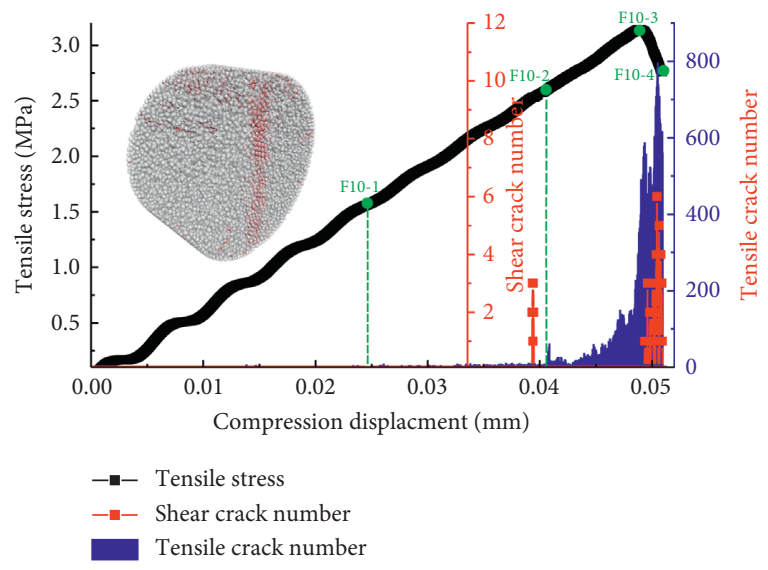

(c)

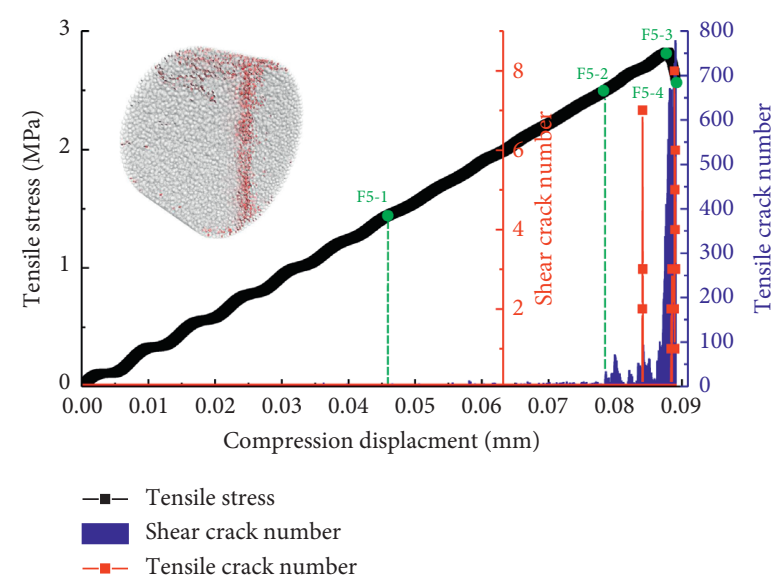

(b)

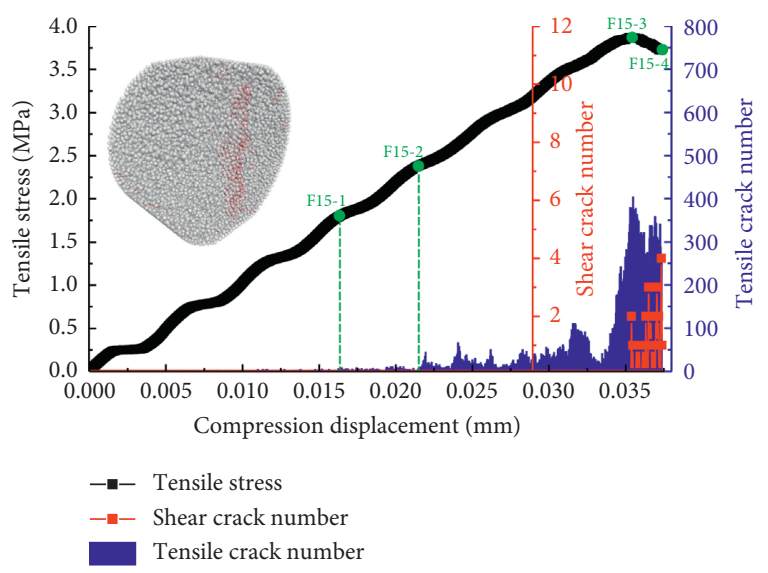

(d)

Figure 13: Typical numerical results of the BT and FBT tests: (a) numerical results of the BT test; (b-d) the FBT tests with the loading angles of $5^{\circ}, 10^{\circ}$, and $15^{\circ}$, respectively.

tensile stress curve (Figure 13(a)). At Point J-1, Figure 14(a) shows that a central tension concentration zone forms on the vertical ABC monitor plane (Figure 9(b)). Some crushed cracks, caused by the concentrated shear stress in Figure 14(a), form near the contacts between the arch jaw and the specimen (Figure 14(e)). At the point J-2, Figure 14(b) clearly shows that the central tensile stress further concentrates. Simultaneously, two tension concentration zones (upper and bottom) form near the upper and bottom contacts. In addition, the crushed microcracks further accumulate (Figure 14(f)). With a further increase in the axial displacement, the tensile stress reaches the peak at the point J-3. Interestingly, the tensile stress between the upper and central tension concentration zones slightly releases (Figure 14(c)). Simultaneously, a crack, composing of continuous microcracks, generates (Figure 14(g)). This phenomenon is similar to the DT test where the crack propagation path overlaps with the tensile stress release zone. Moreover, the tensile stress further concentrates at the tip of the crack. At the point J-4, significant tensile stress releases occur, accompanying with intensive crack propagation (Figures 14(d) and 14(h)). In addition, the shear stresses at the upper and bottom zones simultaneously release. This shear stress release may be responsible for the recorded shear crack generation after the peak (Figure 13(a)).

On the horizontal DEF plane, the tensile stress continuously concentrates near the middle plane at the points J-1 and J-2 (Figures 15(a) and 15(e)) and the rock is intact (Figures 15(e) and 15(f)). With a further increase in the axial displacements, two tension release zones form, accompanying with two cracks (composing of continuous microcracks) (Figures 15(c) and 15(g)). A central tension concentration zone forms at the tip of the crack and then causes further intensive crack propagation on this plane (Figure 15(h)). Then, the subsequent intensive crack propagation causes the significant stress release on the plane (Figure 15(d)).

For the FBT tests with small loading angles $\left(5^{\circ}\right.$ and $\left.10^{\circ}\right)$, similar tensile stress concentrations before the crack propagation and the stress release after the crack propagation (Figures 14 and 15) are observed. When the loading 

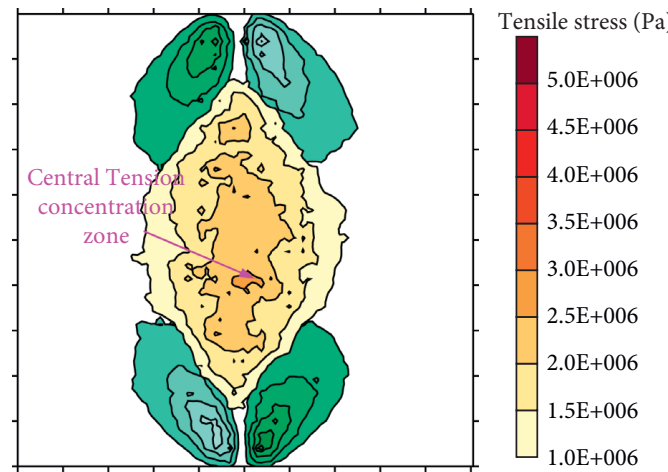

(a)

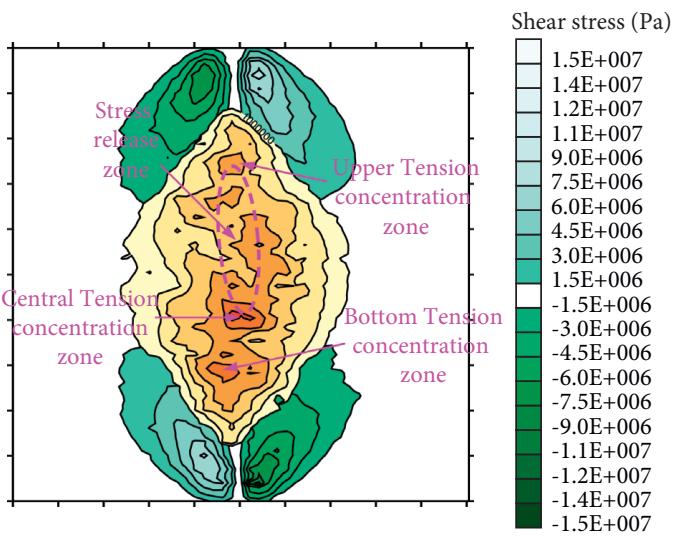

(c)

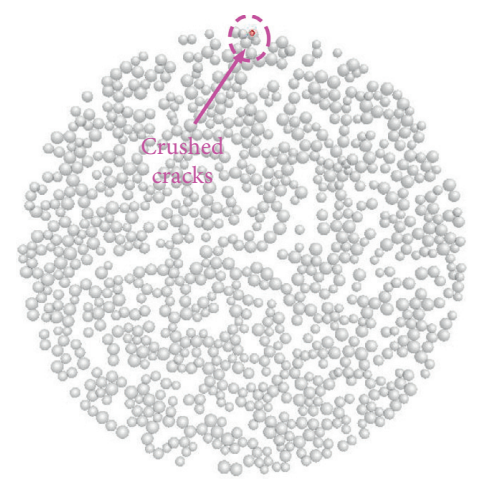

(e)

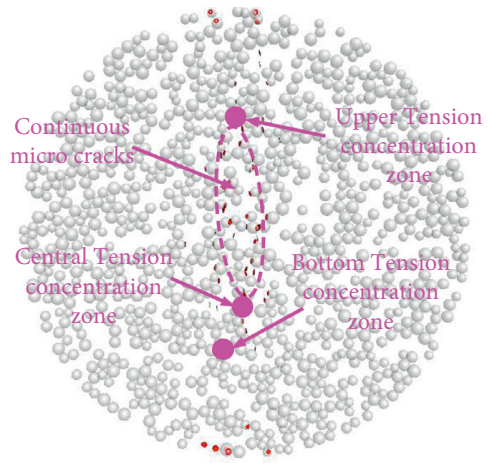

(g)

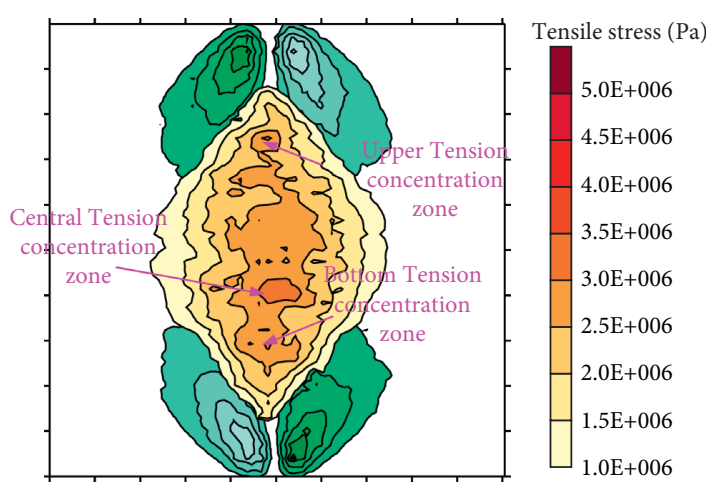

(b)

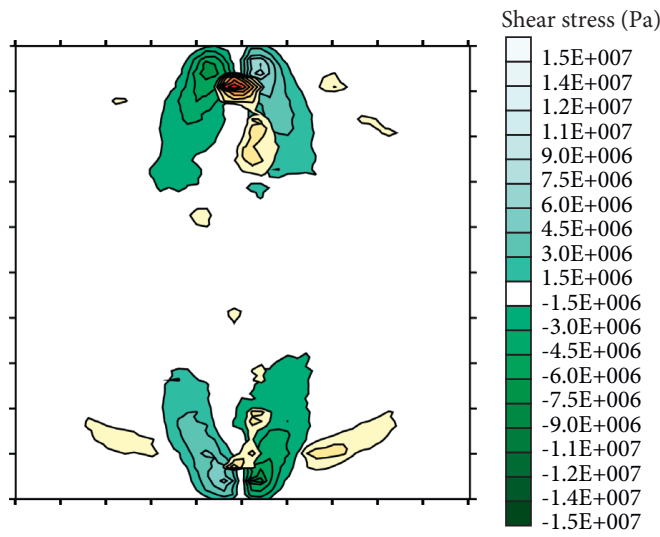

(d)

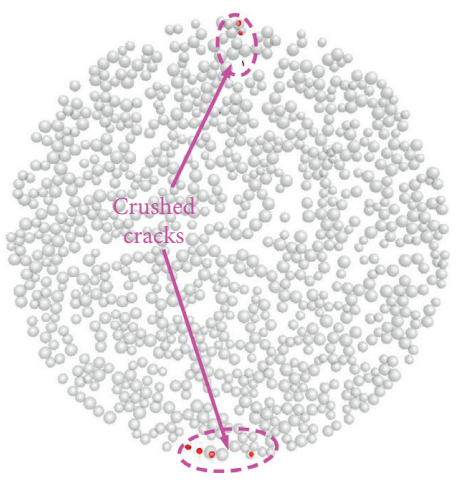

(f)

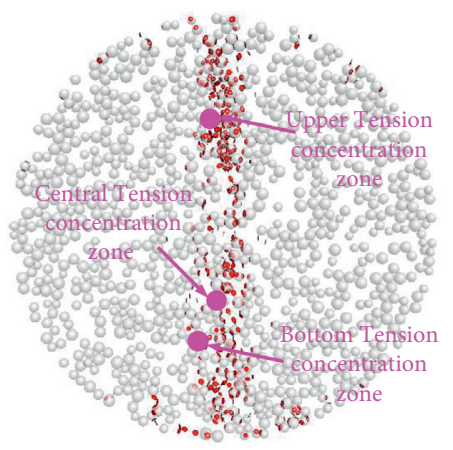

(h)

FIGURE 14: Stress conditions and crack propagations at the monitor points on the vertical ABC plane for the BT tests: (a-d) stress conditions; (e-h) crack propagations. 


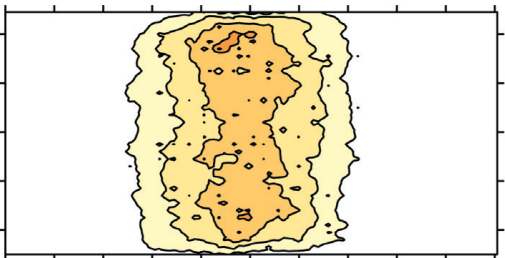

(a)

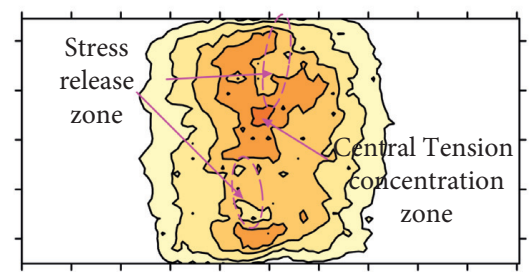

(c)

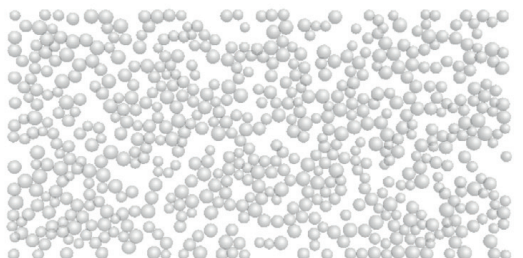

(e)

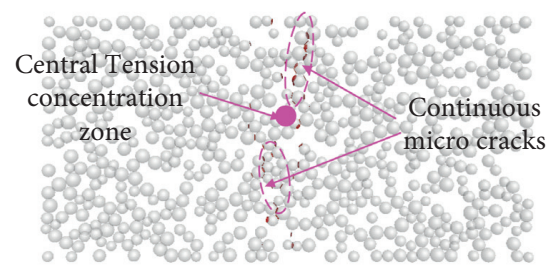

(g)

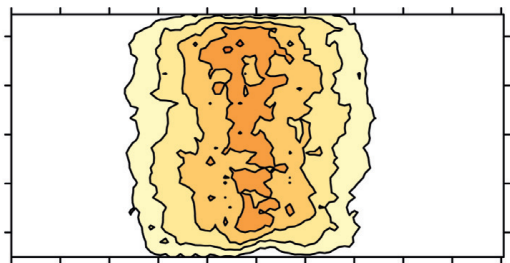

(b)

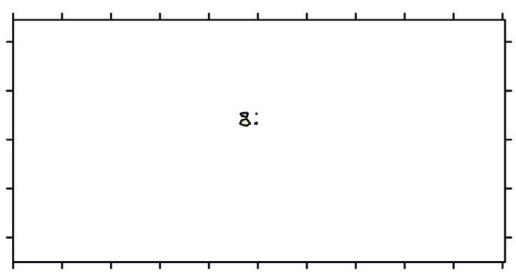

(d)

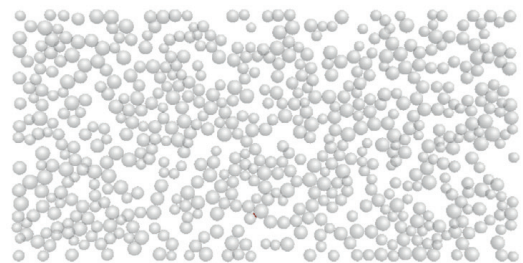

(f)

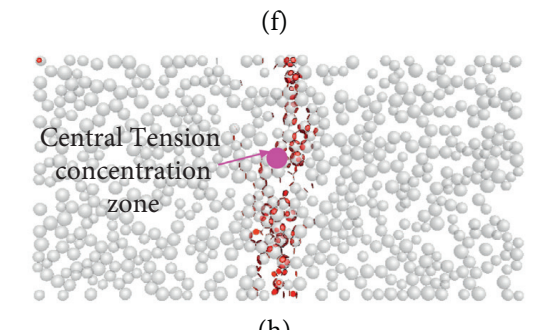

(h)
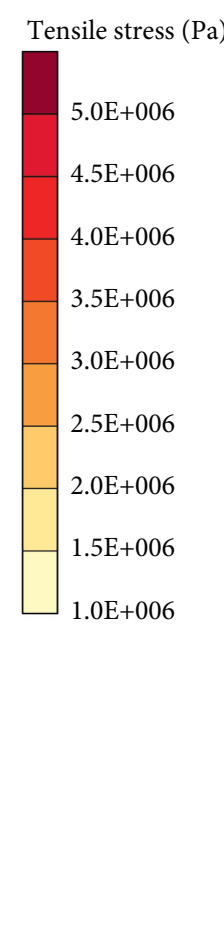

FIGURE 15: Stress conditions and crack propagations at the monitor points on the horizontal DEF plane for the BT tests: (a-d) stress conditions; (e-h) crack propagations.

angle increases to $15^{\circ}$, Figure 13(d) shows that the monitor point F15-2, corresponding to microcrack initiation and accompanying with the decreased slope of the tensile stress, significantly deviates from the peak point F15-3. This phenomenon may relate to the significantly different stress evolutions in Figure 16. Figures 16(a) and 16(b) show that the upper and bottom tension concentration zones are absent. In other words, the tensile stress concentrates at the central part of the vertical monitor plane. Subsequently, cracks, composing of continuous microcracks, form, and the tensile stress concentrates at the tips of these cracks (Figures 16(c) and 16(g)). These concentrations further generate intensive crack propagations, resulting in tensile stress releases (Figures 16(d) and 16(h)). On the DEF plane, similar tensile stress concentrations before the crack propagation and the stress release after the crack propagation (Figure 15) are observed.

The above numerical tests on the BT and FBT tests clearly show that the tensile stress gradually concentrates at the early compression stage. When the tensile stress reaches a critical value, microcracks in small-scale form. However, the initiation stresses for these microcracks deviate from the peak stresses, calculated using the theoretical equations. This phenomenon is reasonable because specimens need additional loading to achieve complete split after the fracture initiation [34]. The above numerical results properly verify the present laboratory results and the laboratory observations by Patel and Wang $[8,23]$. Thus, the practical tensile strength may vary from that calculated using the peak compression force. In addition, for the FBT tests, the variations in the tensile stress concentration conditions (with the increase in the loading angle) may be responsible for the increased deviations. Moreover, by combining the crack propagation in $\mathrm{ABC}$ and EDF planes, it can be inferred that the crack initiation point may deviate from the center of the specimen. In addition, cracks propagate in a spatial manner instead of a plane manner.

\section{Comparison between the Laboratory and Numerical Results}

The above descriptions on numerical results clearly show that tensile cracks develop in different manners for direct and indirect tensile tests. For direct tensile tests, tensile failure occurs at the peak point of the tensile stress and 
Tensile stress $(\mathrm{Pa})$

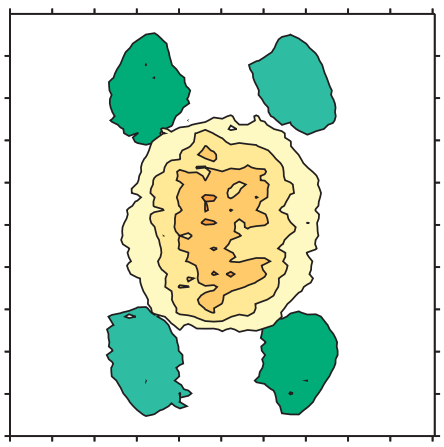

(a)

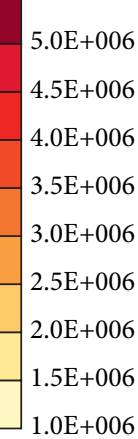

Shear stress $(\mathrm{Pa})$

$\square 1.5 \mathrm{E}+007$

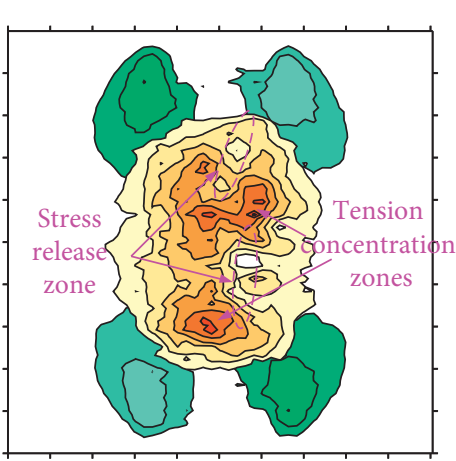

(c)

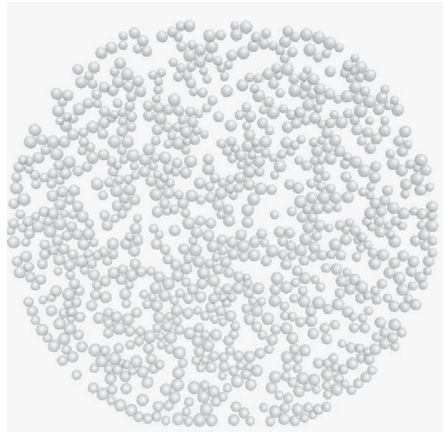

(e)

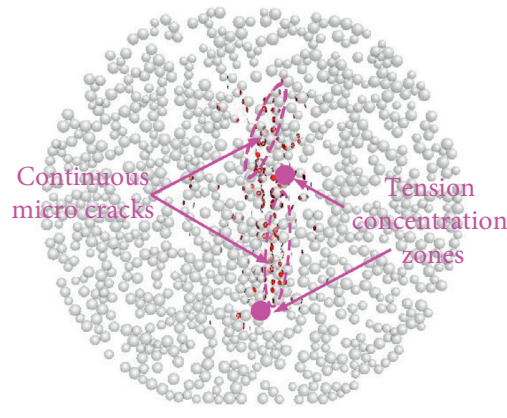

(g)
Tensile stress $(\mathrm{Pa})$

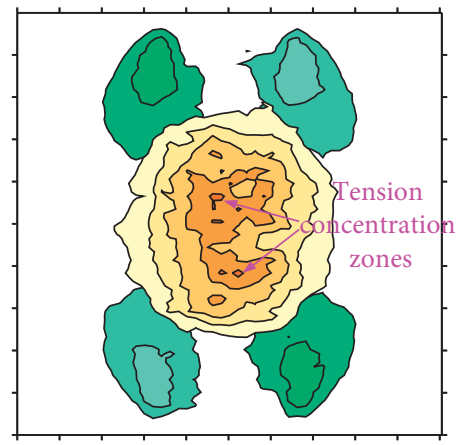

$5.0 \mathrm{E}+006$

$4.5 \mathrm{E}+006$

$4.0 \mathrm{E}+006$

$3.5 \mathrm{E}+006$

$3.0 \mathrm{E}+006$

$2.5 \mathrm{E}+006$

$2.0 \mathrm{E}+006$

$1.5 \mathrm{E}+006$

(b)

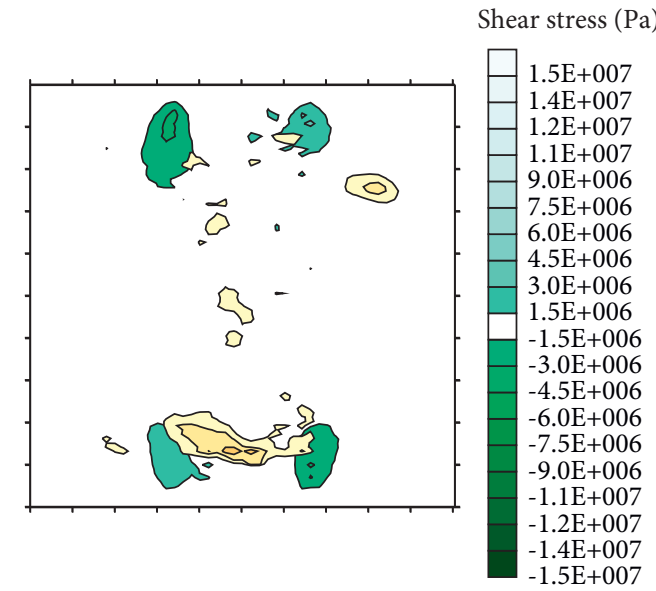

(d)

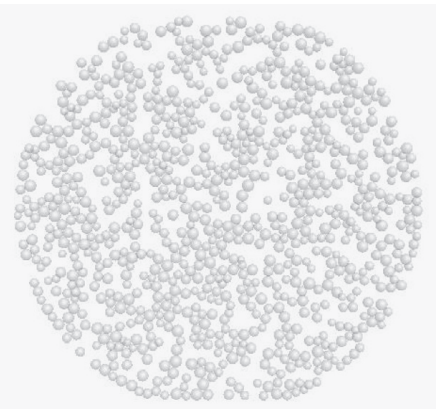

(f)

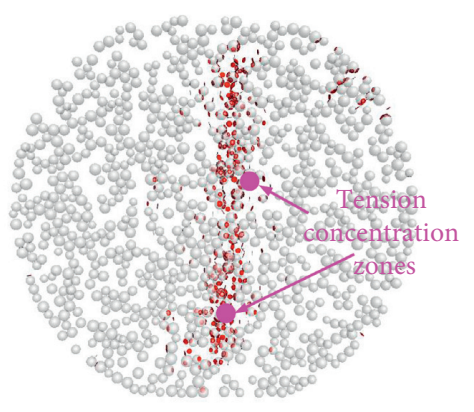

(h)

FIGURE 16: Stress conditions and crack propagations at the monitor points on the vertical ABC plane for the FBT tests $\left(15^{\circ}\right)$ : $(\mathrm{a}-\mathrm{d})$ stress conditions; (e-h) crack propagations. 


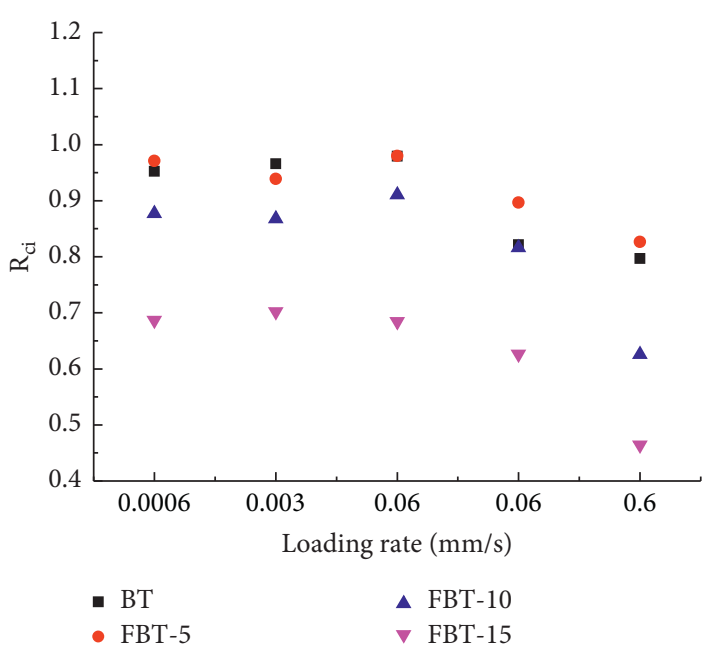

(a)

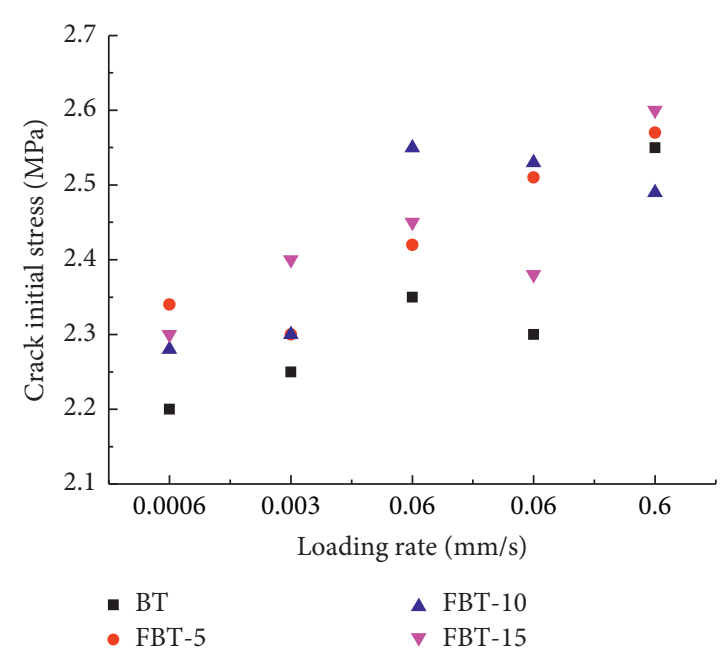

(b)

FIGURE 17: Crack initiation ratios and tensile strengths using the crack initiation stress.

leads to the final failure of the specimen at once. However, for the indirect tensile tests, the tensile crack first initiates and slightly propagates before the peak compression stress. Then, an additional loading is needed to cause the entire failure of the specimen, usually accompanying with the peak compression stress. Thus, the actual initiation points of the indirect tensile tests deviate from the peak points. Our laboratory lacks essential equipment to dynamically record crack propagations. Nevertheless, the above numerical results may show some lights on why the indirect tensile strengths are higher than that of the direct tensile strengths. In addition, for the indirect tensile tests, the stress concentrations correlate to the specimen geometry. The loading rate may further increase the deviations among different indirect tests.

In the present study, the ratio of the crack initiation stress to the peak stress, calculated using equations (2) and (3), is defined as the crack initiation ratio, $R_{c i}$ :

$$
R_{c i}=\frac{S_{c i}}{S_{p}},
$$

where $R_{c i}, S_{c i}$, and $S_{p}$ are the crack initiation ratio, the crack initiation stress, and the peak stress, respectively.

Figure 17(a) shows the crack initiation ratios for various indirect tests. Clearly, the increases in the loading rate and loading angle decrease the crack initiation ratios. In other words, the deviations between the crack initiation stress and the peak stress increase with the increases in the loading rate and loading angle. This phenomenon can explain why the increases in the loading rate and loading angle promote the increase ratio in Figure (7). Using the compression stresses at the crack initiation points, Figure 17(b) shows the calculated crack initiation stresses calculated from equations (2) and (3). Clearly, these crack initiation stresses, ranging from 2.2 $\mathrm{MPa}$ to $2.6 \mathrm{MPa}$, are closer to the DT strengths ranging from 2.0 $\mathrm{MPa}$ to $2.3 \mathrm{MPa}$ (Figure 10).

\section{Conclusions}

The laboratory results agree well with the numerical results, and the indirect tensile strengths are higher than the direct tensile strengths. In addition, the deviations are enlarged with the increase in the loading rate. The dynamic crack propagation study, using PFC $3 \mathrm{D}$, can verify the above phenomenon. For the direct tensile tests, tensile failure occurs at the peak tensile point and results in the final failure of the specimen at once. However, for the indirect tensile tests, the crack initiation point on the loading curve differs from the peak point. In other words, cracks in specimens slightly propagate between the crack initiation and peak point. The subsequent propagation after the peak point is responsible for the final failure of the specimen. In addition, the specimen geometry affects the stress concentration in the indirect tensile tests. It can be concluded that the calculated indirect tensile strengths, using the crack initiation loading instead of the peak loading, are closer to the direct tensile strengths for various loading rates.

\section{Data Availability}

The data used to support the findings of this study are included within the article.

\section{Conflicts of Interest}

The authors declare that they have no conflicts of interest.

\section{Acknowledgments}

The authors would like to acknowledge the following financial supports: projects supported by the National Natural Science Foundation of China (Nos. 51804110 and 52004327), and projects supported by the Natural Science Foundation of Hunan Province (Nos. 2020JJ5101 and 2019JJ40056) and Scientific Research Foundation of Hunan 
Province Education Department (Nos. 18B391, 18A345, 19B124, and 19A114).

\section{References}

[1] A. Neogi, M. Alam, A. Hartmaier, and R. Janisch, "Anisotropic failure behavior of ordered intermetallic TiAl alloys under pure Mode-I loading," Modelling and Simulation in Materials Science and Engineering, vol. 28, no. 6, Article ID 065016, 2020.

[2] J. Yu, X. Shang, and P. Wu, "Influence of pressure distribution and friction on determining mechanical properties in the Brazilian test: theory and experiment," International Journal of Solids and Structures, vol. 161, pp. 11-22, 2019.

[3] G. Xu, C. He, Z. Chen, and D. Wu, "Effects of the microstructure and micro-parameters on the mechanical behaviour of transversely isotropic rock in Brazilian tests," Acta Geotechnica, vol. 13, no. 4, pp. 887-910, 2018.

[4] H. Li, J. Li, B. Liu, J. Li, S. Li, and X. Xia, "Direct tension test for rock material under different strain rates at quasi-static loads," Rock Mechanics and Rock Engineering, vol. 46, no. 5, pp. 1247-1254, 2013.

[5] D. Cen, D. Huang, Y. Song, and Q. Jiang, "Direct tensile behavior of limestone and sandstone with bedding planes at different strain rates," Rock Mechanics and Rock Engineering, vol. 53, no. 6, pp. 2643-2651, 2020.

[6] X. Chang, J. Tang, G. Wang, and C. Tang, "Mechanical performances of rock-like disc containing circular inclusion subjected to diametral compression," Archives of Civil and Mechanical Engineering, vol. 18, no. 2, pp. 356-370, 2018.

[7] S. Qi, H. Lan, D. Martin, and X. Huang, "Factors controlling the difference in Brazilian and direct tensile strengths of the Lac du Bonnet granite," Rock Mechanics and Rock Engineering, vol. 53, no. 3, pp. 1005-1019, 2019.

[8] Y.-S. Wang, J.-H. Deng, L.-R. Li, and Z.-H. Zhang, "Microfailure analysis of direct and flat loading Brazilian tensile tests," Rock Mechanics and Rock Engineering, vol. 52, no. 11, pp. 4175-4187, 2019.

[9] Z. Aliabadian, G.-F. Zhao, and A. R. Russell, "Crack development in transversely isotropic sandstone discs subjected to Brazilian tests observed using digital image correlation," International Journal of Rock Mechanics and Mining Sciences, vol. 119, pp. 211-221, 2019.

[10] D. Li and L. N. Y. Wong, "The Brazilian disc test for rock mechanics applications: review and new insights," Rock Mechanics and Rock Engineering, vol. 46, no. 2, pp. 269-287, 2012.

[11] Y. Yu and C. Y. Meng, "3-D distribution of tensile stress in rock specimens for the Brazilian test," J Univ Sci Technol Beijing Miner Metall Mater (Eng Ed), vol. 12, no. 6, pp. 495-499, 2005.

[12] M. Bahaaddini, M. Serati, H. Masoumi, and E. Rahimi, "Numerical assessment of rupture mechanisms in Brazilian test of brittle materials," International Journal of Solids and Structures, vol. 180-181, pp. 1-12, 2019.

[13] Y. Dai, Y. Li, X. Xu et al., "Fracture behaviour of magnesia refractory materials in tension with the Brazilian test," Journal of the European Ceramic Society, vol. 39, no. 16, pp. 54335441, 2019.

[14] C. C. Garcia-Fernandez, C. Gonzalez-Nicieza, M. I. AlvarezFernandez, and R. A. Gutierrez-Moizant, "New methodology for estimating the shear strength of layering in slate by using the Brazilian test," Bulletin of Engineering Geology and the Environment, vol. 78, no. 4, pp. 2283-2297, 2018.
[15] D. Guha Roy and T. N. Singh, "Effect of heat treatment and layer orientation on the tensile strength of a crystalline rock under Brazilian test condition," Rock Mechanics and Rock Engineering, vol. 49, no. 5, pp. 1663-1677, 2015.

[16] J. He and L. O. Afolagboye, "Influence of layer orientation and interlayer bonding force on the mechanical behavior of shale under Brazilian test conditions," Acta Mechanica Sinica, vol. 34, no. 2, pp. 349-358, 2017.

[17] M. Wang and P. Cao, "Experimental study on the validity and rationality of four Brazilian disc tests," Geotechnical \& Geological Engineering, vol. 36, no. 1, pp. 63-76, 2017.

[18] ASTM, Standard test method for splitting tensile strength of intact rock core specimens, ASTM, West Conshohocken, PA, US, 1988.

[19] Q. Z. Wang, X. M. Jia, S. Q. Kou, Z. X. Zhang, and P.-A. Lindqvist, "The flattened Brazilian disc specimen used for testing elastic modulus, tensile strength and fracture toughness of brittle rocks: analytical and numerical results," International Journal of Rock Mechanics and Mining Sciences, vol. 41, no. 2, pp. 245-253, 2004.

[20] X. Tan, H. Konietzky, T. Frühwirt, and D. Q. Dan, "Brazilian tests on transversely isotropic rocks: laboratory testing and numerical simulations," Rock Mechanics and Rock Engineering, vol. 48, no. 4, pp. 1341-1351, 2014.

[21] G. Xu, C. He, Z. Chen, and A. Su, "Transverse isotropy of phyllite under Brazilian tests: laboratory testing and numerical simulations," Rock Mechanics and Rock Engineering, vol. 51, no. 4, pp. 1111-1135, 2017.

[22] S. Wu, J. Ma, Y. Cheng, M. Xu, and X. Huang, "Numerical analysis of the flattened Brazilian test: failure process, recommended geometric parameters and loading conditions," Engineering Fracture Mechanics, vol. 204, pp. 288-305, 2018.

[23] S. Patel and C. D. Martin, "Application of flattened Brazilian test to investigate rocks under confined extension," Rock Mechanics and Rock Engineering, vol. 51, no. 12, pp. 37193736, 2018.

[24] L. X. Xiong and H. J. Chen, "Effects of high temperatures and loading rates on the splitting tensile strength of jointed rock mass," Geotechnical \& Geological Engineering, vol. 38, no. 2, pp. 1885-1898, 2019.

[25] J.-J. Wang, Y.-Q. Li, F.-X. Jian, and D. Huang, "Rate dependence of splitting tensile behaviors of sandstone and mudstone," Geotechnical \& Geological Engineering, vol. 37, no. 4, pp. 3469-3475, 2019.

[26] R. H. Cao, P. Cao, H. Lin, G. W. Ma, C. Y. Zhang, and C. Jiang, "Failure characteristics of jointed rock-like material containing multi-joints under a compressive-shear test: experimental and numerical analyses," Archives of Civil and Mechanical Engineering, vol. 18, no. 3, pp. 784-798, 2018.

[27] T. Belytschko, L. Gu, and Y. Y. Lu, "Fracture and crack growth by element free Galerkin methods," Modelling and Simulation in Materials Science and Engineering, vol. 2, no. 3A, pp. 519-534, 1994.

[28] J. Liu, J. Wang, and W. Wan, "Numerical study of crack propagation in an indented rock specimen," Computers and Geotechnics, vol. 96, pp. 1-11, 2018.

[29] A. Jagota and S. J. Bennison, "Element breaking rules in computational models for brittle fracture," Modelling and Simulation in Materials Science and Engineering, vol. 3, no. 4, pp. 485-501, 1999.

[30] J. Liu, W. Wan, Y. Zhao, and X. Fan, "Stress evolution in punch-through shear tests: a numerical study based on discrete element method," Frontiers in Physics, vol. 8, 2020. 
[31] X.-X. Yang and W.-G. Qiao, "Numerical investigation of the shear behavior of granite materials containing discontinuous joints by utilizing the flat-joint model," Computers and Geotechnics, vol. 104, pp. 69-80, 2018.

[32] R.-h. Cao, P. Cao, H. Lin, C.-z. Pu, and K. Ou, "Mechanical behavior of brittle rock-like specimens with pre-existing fissures under uniaxial loading: experimental studies and particle mechanics approach," Rock Mechanics and Rock Engineering, vol. 49, no. 3, pp. 763-783, 2015.

[33] H. Y. Wu, J. Kemeny, and S. C. Wu, "Experimental and numerical investigation of the punch-through shear test for mode II fracture toughness determination in rock," Engineering Fracture Mechanics, vol. 184, no. 59-74, 2017.

[34] E. Hoek and C. D. Martin, "Fracture initiation and propagation in intact rock - a review," Journal of Rock Mechanics and Geotechnical Engineering, vol. 6, no. 4, pp. 287-300, 2014. 